\title{
Determinants of Intention to Use eLearning Based on the Technology Acceptance Model
}

\author{
Alfie Chacko Punnoose \\ Faculty of Science and Technology, Assumption University, \\ Bangkok, Thailand
}

\author{
apunnoose@au.edu
}

\section{Executive Summary}

The purpose of this study was to find some of the predominant factors that determine the intention of students to use eLearning in the future. Since eLearning is not just a technology acceptance decision but also involves cognition, this study extended its search beyond the normal technology acceptance variables into variables that could affect the cognition of an individual due to his or her unique characteristics.

The variables in the literature of technology acceptance studies can be classified broadly into 5 categories. They are Individual Differences, Beliefs, Attitude, Behavioral Intention, and Actual Behavior. Since the Technology Acceptance Model (TAM) is the most widely used model to study the acceptance of technology, this study adopted TAM and further extended it based on the recommendations from the literature of information systems and information technology.

It can be said that eLearning is in the 'Early Adopters' stage in the academic sector and at the 'Early Majority' stage in the corporate sector of the innovation diffusion process. Individual differences are among the external variables said to influence the belief variables in TAM. The research intent is to understand what individual differences can be observed as the characteristics of early adopters of eLearning. Personality traits are one of the predominant measures of individual differences. This study employs the big five personality trait measures to measure the personality types of individuals engaged in eLearning and how they influence their decision to further engaging in eLearning. The variables of the research model are categorized into individual differences, beliefs and behavior. Apart from the TAM variables, i.e., Perceived Ease of Use (PEU) and Perceived Usefulness (PU), this study has incorporated Perceived Enjoyment (PE) which is a measure of intrinsic motivation and Subjective Norms (SN) into the beliefs variables category.

This research was conducted among the master degree students of eLearning programs at a University in Thailand. There are 750 students who have completed or are currently enrolled in these programs at the university. The students comprise both Thai national and international students. A total of 249 usable questionnaires were collected. The respondents studied in eLearning master

Material published as part of this publication, either on-line or in print, is copyrighted by the Informing Science Institute. Permission to make digital or paper copy of part or all of these works for personal or classroom use is granted without fee provided that the copies are not made or distributed for profit or commercial advantage AND that copies 1) bear this notice in full and 2) give the full citation on the first page. It is permissible to abstract these works so long as credit is given. To copy in all other cases or to republish or to post on a server or to redistribute to lists requires specific permission and payment of a fee. Contact Publisher@InformingScience.org to request redistribution permission. degree programs from a total of 26 different countries with majority of the respondents ( 83 percent) residing in Thailand. Most of the respondents (67 percent) had no prior experience with eLearning and the majority (64 percent) of respondents were females. Compared to the females, the males enjoyed eLearning more and expressed stronger intentions to use eLearning in the future. Respondents with prior eLearning expe- 
rience had stronger intentions to use eLearning in the future than those without prior experience.

Analysis of the data shows that the significant predictors of Behavioral Intention (BI) to engage in eLearning are PU, SN, and PEU. Perceived Enjoyment seems to have no significant effect on $\mathrm{BI}$ or beliefs regarding eLearning use. Only three out of the five personality trait variables turned out to be significant in the final model, i.e., Extraversion, Conscientiousness, and Neuroticism. It was found that the effects of individual differences on Behavioral Intention were mediated solely through the belief variables in the final model. Hence it could be concluded that individual differences form beliefs which in turn manifest as the Behavioral Intention of an individual to engage in eLearning.

Keywords: eLearning, Technology Acceptance, Big Five Personality Trait, Motivation, Beliefs, Behavior, Perceived Ease of Use, Perceived Usefulness, Perceived Enjoyment, Subjective Norms

\section{Introduction}

Information is the lifeblood of modern society, and it is the internet that acts as the veins of society keeping the vast amount of information circulating. It has helped us come together without borders and boundaries and has opened up new possibilities. The Internet defies the idea of ownership, which man has cultivated over thousands of years. According to Internet World Statistics (Internet Users in Asia, 2011) the average growth rate of Internet users in the world is $47.67 \%$ calculated over a period of 11 years from 2000 to 2011. The growth rate of Asian internet users surpasses that of the world at $64.26 \%$, with Thailand having the highest growth rate in Asia at $74 \%$.

Technology is revolutionizing education just as it is doing with all aspects of human life. The Internet is helping people learn informally by sharing information and facilitating communication by connecting people. These and other advantages of the internet and associated technologies are being merged to support education and training so as to improve and overcome the limitations of traditional learning methods.

The concept of online learning predates the appearance of the Web, but most recent publications about online learning refer to materials delivered over the Internet or Intranets (e.g., Malopinsky, Kirkley, Stein, \& Duffy, 2000; Schank, 2001).Web-based learning, online learning, and distance learning are widely used as interchangeable terms. However, these terms represent concepts with subtle, yet consequential differences (Tsai \& Machado, 2002). eLearning is the latest term added to this list and have mostly replaced all other terms. eLearning is mostly associated with activities involving computers and interactive networks simultaneously. Though the computer and the network do not need to be the central elements of the activity or provide learning content, they hold a significant involvement in the learning activity (Tsai \& Machado, 2002). Schank (2001) refers to learning activities involving computer networks as eLearning and stresses that eLearning is not merely distance learning. Much literature associates eLearning with Web-based learning over the Internet (Driscoll, 2002; Horton, 2000; Rosenberg, 2000). At this time in human history when technology is evolving at a breathtaking pace, the definition of eLearning must not be associated with a particular technology. Maldonado, Khan, Moon, and Rho (2011) define eLearning as the delivery of education and training through information and communication technologies. More specifically, eLearning is the employment of advancements in electronic technology to create, deliver, and manage learning content, to facilitate communication and collaboration between parties involved, and to manage the learning activity itself.

The eLearning market is among the most rapidly growing sectors in the worldwide education and training industry (Jose, 2010). eLearning holds an edge over other computer-based training initiatives due to its ability to lower costs by centralizing content, reducing logistics costs, facilitating persistent storage, and enabling uniformity in content delivery. Continuous developments over 
the years have allowed eLearning to emerge as a critical medium for learning, allowing companies to lower recurring costs. eLearning also offers additional qualitative benefits, unlike conventional methods, in the form of anytime/anywhere learning, access to worldwide mentoring resources for maximum skill development, and administration and control of the training calendar from several locations(Jose, 2010).

Despite all the advantages and benefits of eLearning, to successfully be accepted and adopted by individuals we need to identify the factors that formulate their behavior in favor of eLearning. The success of online learning programs depends not only on students' satisfaction but also their intent to continue using it (Brahmasrene \& Lee, 2012). Thus this study addresses the following four related research questions:

1. What are the factors that affect an individual's intention to study in an eLearning mode?

2. What are the relationships among the factors identified in question 1 that affect an individual's intention to study in an eLearning mode?

3. Among the factors and relationships that affect an individual's intention to study in an eLearning mode, which factors are the most important and which are the significant causal relationships?

4. What are the theoretical and practical implications of the research findings?

\section{Research Design and Methodology}

This study aims to develop theoretical knowledge with practical implications about causal relationships among variables derived from previous studies concerned with the behavioral intention of further engagement in eLearning. The variables measure the individual characteristics and perceptions of the students based on their experience in studying in an eLearning Master Degree program. These variables are measured at a single point in time using a self-administered questionnaire.

Research questions 1 and 2 are addressed by reviewing existing theory derived from previous studies to formulate a theoretical model of the factors and the causal relationships among them. Question 3 is addressed by testing the theoretical model using data collected from a sample of eLearning students and by developing the model using structural equation modeling techniques to arrive at a final parsimonious model. In order to address research question 4 , the results in the final model are interpreted and compared with the results from previous studies and practical conclusions are drawn.

The unit of analysis in this study was an individual who is undertaking or has completed a master degree program in eLearning mode at Assumption University of Thailand. Assumption University of Thailand is the first international university, and also the first to introduce government accredited eLearning degree programs, in Thailand. The medium of instruction for all courses taught at the university is English. As of 2012, the University offers three master degree programs and two Ph.D. programs in the eLearning mode. To be admitted to an eLearning degree program

the students must demonstrate their competence in the English language, either by providing valid scores for tests such as TOEFL or IELTS or by passing the English Proficiency Test conducted by the university. The population of the individuals of this study at Assumption University numbers 750 . The minimum sample size for random sampling is estimated to be 240 by the procedure recommended by Tryfos (1996). This sample size also satisfies the criteria for the use of descriptive statistics and structural equation modeling (SEM) techniques used in the study.

A self-administered, structured questionnaire designed to measure the variables in the theoretical model was prepared in the English language. The questionnaire uses measurement instruments used in previous studies, as shown in Table 1 later in this paper, in order to improve the validity 
and reliability of the measures. The questionnaire is structured in four sections. The first section measures variables intended to provide a profile of the characteristics of the respondents and includes gender, prior experience with eLearning, and country of residence during the study. The next three sections (the second through fourth sections) measure variables included in the theoretical model. The second section measures questions related to understanding the individual differences of the respondents, which includes Personality Trait and Computer Self-Efficacy (CSE). Personality Traits are measured using the Big Five Personality Trait measures of Costa and McCrae (1992). The third section measures the beliefs of the respondents regarding eLearning. This section measures variables such as Perceived Ease of Use (PEU), Perceived Usefulness (PU), Perceived Enjoyment (PE), and Subjective Norms (SN). The fourth and final section measures the respondent's Behavioral Intention (BI) to use eLearning. The column named "Indicators" in Table 1 shows the label of indicators along with the number of indicators used to measure each variable. Perceived Enjoyment is the variable measured with the least number of indicators (3 indicators) and Computer Self-Efficacy with the most indicators (10 indicators). The notated questionnaire can be found in the Appendix, which provides the details of the instruments used.

The questionnaire was reviewed by a focus group of 5 users of eLearning systems representative of the target population. Suggested modifications were incorporated in a revised version of the questionnaire, which was then administered in a pilot study using a sample of 10 suitable participants. Their responses and comments were noted and modifications were incorporated into the final version of the questionnaire.

The questionnaire was designed and developed as an online application. The links for the questionnaire were sent to every student with a personalized message, which addressed each student individually. The IP address of each response was tracked to avoid duplicated entries, and the time taken for each student was recorded to identify non-genuine responses. The questionnaire was divided into four sections based on the classification of the model variables; Profile of the Respondents, Individual Differences, Beliefs, and Behavioral Intention.

\section{Literature Review and Hypothesis Development}

The Technology Acceptance Model (TAM) is an adaptation of the Theory of Reasoned Action (TRA) to the field of Information Systems (IS). TAM is theoretically customized for the study of computer-technology acceptance with a high research significance in the IS discipline (Straub, Keil, \& Brenner, 1997, Taylor \& Todd, 1995). TAM is capable of explaining user behavior across a broad range of end-user computing technologies and user populations, while at the same time being both parsimonious and theoretically justified (Lee, Cheung, \& Chen, 2005). TAM posits that Perceived Usefulness and Perceived Ease of Use determine an individual's intention to use a system, with intention to use serving as a mediator of actual system use. Perceived Usefulness is also seen as being directly impacted by Perceived Ease of Use (Davis, 1989).

Researchers have simplified TAM by removing the attitude construct found in TRA from the current specification (Venkatesh, Morris, Davis, \& Davis, 2003). Attempts to extend TAM have generally taken one of three approaches: by introducing factors from related models, by introducing additional or alternative belief factors, and by examining antecedents and moderators of Perceived Usefulness and Perceived Ease of Use (Wixom \& Todd, 2005).

Comparison of some of the different models used for technology acceptance studies and some models from which these models are derived is shown in Figure 1. The comparison shows that the variables of these models can be grouped into five categories: Individual Differences, Beliefs, Attitude, Behavioral Intention, and Actual Behavior. 
This research introduces personality traits as antecedents of belief factors because motivated behavior is primarily a function of individual characteristics (Weinberg \& Gould, 2010). The study also introduces alternative belief factors such as Perceived Enjoyment and Subjective Norms apart from TAM's Perceived Usefulness and Perceived Ease of Use. The variables incorporated in this study are divided into three categories: Individual Differences, Beliefs, and Behavior.

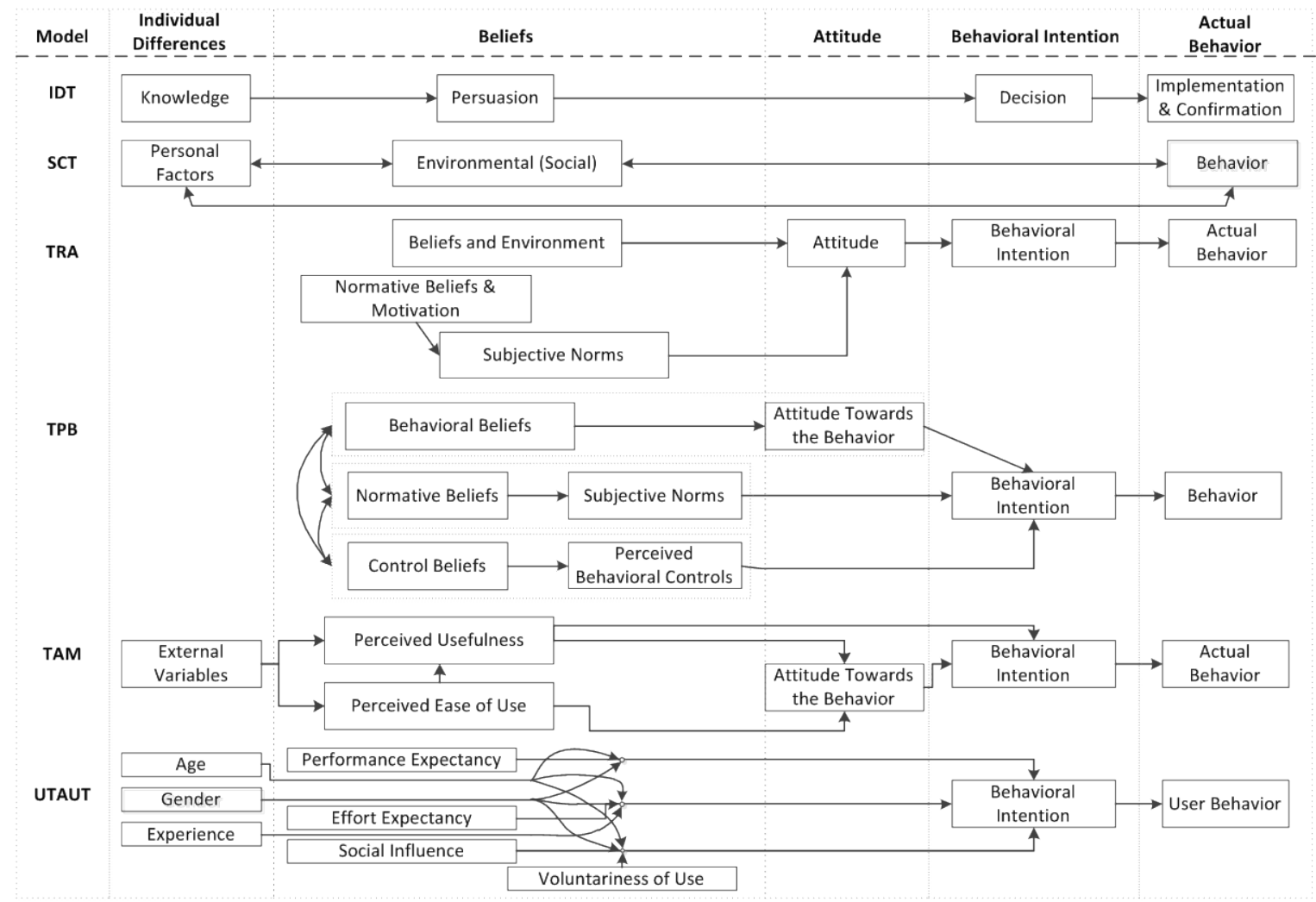

Figure 1: Comparison of Innovation Diffusion Theory (IDT), Social Cognitive Theory (SCT), Theory of Reasoned Action (TRA), Theory of Planned Behavior (TPB), Technology Acceptance Model (TAM) and Unified Theory of Acceptance and Use of Technology (UTAUT).

\section{Behavior and Behavioral Intention (BI)}

The primary purpose of this research was to investigate what factors drive the Behavioral Intention of students of eLearning degree programs to continue utilizing eLearning as a mode of learning in the future. Intention is an indicator used to capture the factors that influence a desired behavior (Ajzen, 1991). TRA states that Behavioral Intention is the cognitive representation of a person's readiness to perform a given behavior, and it is considered to be the immediate antecedent of behavior. Behavior intention indicates how much effort an individual would like to commit to perform such behavior. People consider the implications of their actual behavior before they decide to engage or not engage in a given behavior (Ajzen \& Fishbein, 1980, p. 5). Higher commitment is more likely to mean that behavior would be performed. The TRA suggests that a person's behavioral intention depends on the person's attitude about the behavior and Subjective Norms (Fishbein \& Ajzen, 1975). There are several factors such as Perceived Enjoyment (Wang, Lin, \& Liao, 2010), Perceived Usefulness (Davis, 1989), Openness to Experience (Jacques, Garger, Brown, \& Deale, 2009) and Subjective Norms (Schepers \& Wetzel, 2007) that are positively associated with behavioral intention (intention to use a technology). 


\section{Beliefs}

Belief is the psychological state in which an individual holds a proposition or premise to be true. Contemporary analytic philosophers generally use the term "belief" to refer to the attitude we have, roughly, whenever we take something to be the case or regard it as true (Schwitzgebel, 2011).

Motivation is the psychological feature that arouses an organism to action toward a desired goal and elicits, controls, and sustains certain goal directed behaviors (WordNet Search, n.d.). Motivated behavior is primarily a function of individual characteristics such as needs, interests, goals, and personality (Weinberg \& Gould, 2010). In Self-Determination Theory (Deci \& Ryan, 1985) motivation is distinguished into two types based on the different reasons or goals that give rise to an action. The most basic distinction is between intrinsic motivation, which refers to doing something because it is inherently interesting or enjoyable, and extrinsic motivation, which refers to doing something because it leads to a separable outcome. Intrinsic motivation is defined as the doing of an activity for its inherent satisfaction rather than for some separable consequence. Researchers suggest that extrinsic and intrinsic motivators jointly determine the adoption of new technologies (Saadé, Tan, \& Nebebe, 2008).

\section{Perceived Usefulness (PU)}

Extrinsic motivation is a construct that pertains whenever an activity is done in order to attain some separable outcome (Ryan \& Deci, 2000). Extrinsic motivation emphasizes performing a behavior to achieve specific goals or rewards (Vallerand, 1997). Perceived Usefulness in the technology acceptance model is an example of extrinsic motivation (Davis, Bagozzi, \& Warshaw, 1992). Perceived Usefulness is a key driver of usage behavior and intention. Perceived Usefulness refers to "the degree to which a person believes that using a particular system would enhance his or her performance" (Davis, 1989). Davis (1989) also found that Perceived Usefulness was more important in Western cultures.

eLearning provides the students the flexibility of learning from anywhere at any time at one's own convenience. It enables students to learn at their own pace. eLearning set the stage for people who are geographically apart to come together to learn, collaborate, and share knowledge. Those who find eLearning to be useful are more likely to use it as a mode of learning.

H1. Perceived Usefulness has a significantly positive and direct effect on Behavioral Intention.

\section{Perceived Enjoyment (PE)}

Intrinsic motivation refers to the pleasure and satisfaction gained from performing a behavior (Doll \& Ajzen, 1992). When intrinsically motivated, a person is moved to act for the fun or challenge entailed rather than because of external prods, pressures, or rewards (Ryan \& Deci, 2000). From birth onward, humans, in their healthiest states, are active, inquisitive, curious, and playful creatures, displaying a ubiquitous readiness to learn and explore, and they do not require extraneous incentives to do so (Ryan \& Deci, 2000). Intrinsic motivators representing a student's subjective feelings of joy, elation, pleasure, and positive holistic experience also play a critical role in explaining user acceptance and usage behavior of web-based learning (Saadé et al., 2008). Prior studies have proposed that intrinsic motivators, such as Perceived Enjoyment (Davis et al., 1992 and van der Heijden, 2004) can explain the behavioral intention to use information systems.

Saade et al. (2008) used the enjoyment construct to conceptualize students' intrinsic motivation to use web-based learning. His results showed that Perceived Usefulness and enjoyment have significant impact on student intention to use web-based learning systems. Enjoyment refers to the extent to which the activity of using the computer is perceived to be enjoyable in its own right. Wang et al. (2010) found that Perceived Enjoyment was a significant determinant of blogging 
intention. Individuals who are high in Perceived Enjoyment of blogging will exhibit a higher level of behavioral intention to write a blog than individuals who are low in Perceived Enjoyment of blogging (Wang et al., 2010). Venkatesh, Speier, \& Morris (2002) posited that individuals who are more intrinsically motivated may use a new technology for the enjoyment they find in the activity and, since they enjoy the process, they may tend to underestimate its difficulty and find it easier to use.

eLearning students have better control over the learning process compared to traditional students who learn in classrooms. They can review the lectures as many times as they want, they can control learning at their own pace. Electronic lecture notes can easily be searched, edited, or formatted to one's needs. Audio lectures can be carried on mobile devices and listened to while engaged in other activities or during regular commuting. When more technology is incorporated into learning, eLearning can be more enjoyable than traditional classroom learning. Thus, if a student perceives eLearning as enjoyable, he or she is likely to have a higher degree of intention to use it.

H2. Perceived Enjoyment has a significantly positive and direct effect on Behavioral Intention.

\section{Subjective Norms (SN)}

Fishbein and Ajzen (1975) defined subjective norm as a person's perception that most people who are important to them think they should or should not perform the behavior in question. People will generally intend to perform a behavior when they have a positive attitude toward it and when they believe that important individuals think they should do so (Ajzen, 1988). Subjective Norms and image are important determinants of behavioral intentions because they reflect the influence of others and the importance of having others think positively of them.

If conscientious personalities think that significant others believe that the technology should be used, they will form stronger intentions to use the technology (Devaraj, Easley, \& Crant, 2008). The theory of reasoned action also proposes that attitudes and Subjective Norms are influenced by more distal factors such as personality traits (Ajzen, 1988; Connor \& Abraham 2001).

Subjective Norm refers to a person's perception of normative beliefs (e.g., perceived pressures and motivation to pursue) and how most people who are important to him/her think he/she should or should not perform the behavior in question (Fishbein \& Ajzen, 1975, p. 302; Huang, Davison, $\& \mathrm{Gu}, 2008$ ). According to TRA, a person's performance of a specified behavior is determined by his or her Behavioral Intention (BI) to perform the behavior, and BI is jointly determined by the person's Attitude towards using and Subjective Norm concerning the behavior in question. Metaanalysis by Schepers \& Wetzels (2007) found large effect sizes for the correlation between Subjective Norms and Behavioral Intention. If a student thinks his/her family and friends accept and appreciate him/her engaging in eLearning, he or she is likely to enact it.

H3. Subjective Norms has a significantly positive and direct effect on Behavioral Intention.

H4. Subjective Norms has a significantly positive and direct effect on Perceived Usefulness.

\section{Perceived Ease of Use (PEU)}

Perceived Ease of Use is the degree to which a person believes that using a particular system would be free from effort (Davis, 1989). Lee et al. (2005) found that Perceived Ease of Use influenced student intention to use internet-based learning indirectly through Perceived Usefulness and Perceived Enjoyment. Gong, $\mathrm{Xu}$, and Yu (2004) found that Perceived Ease of Use has a significant effect on students' attitudes and Perceived Usefulness simultaneously. The effect of Perceived Ease of Use on Perceived Usefulness is as postulated by TAM.

H5. Perceived Ease of Use has a significantly positive and direct effect on Perceived Enjoyment. 
H6. Perceived Ease of Use has a significantly positive and direct effect on Perceived Usefulness.

\section{Individual Differences}

Individual differences are user factors that include traits such as personality and demographic variables, as well as situational variables that account for differences attributable to circumstances such as experience and training (Agarwal \& Prasad, 1999). Personality is an exogenous variable in a model linking external variables to behavior; in particular, personality is hypothesized to lead to beliefs related to the behavior (Devaraj et al., 2008). In the literature of personality and individual differences, the core aspects of personality are best described by the Big Five Personality (BFP) factors involving Extraversion, Neuroticism, Openness to experience, Agreeableness, and Conscientiousness (Costa \& McCrae 1992; Duff, Boyle, Dunleavy, \& Ferguson, 2004; Petrides et al., 2010). Therefore this research employs the Big Five Personality factors to measure user personality.

\section{Openness (OP)}

Openness is the degree to which an individual is original, curious about many things, and inventive (John \& Srivastava, 1999; McCrae, 1994; Piedmont, 1998). Individuals described as high on the openness-to-experience dimension of personality actively seek out new and varied experiences, and value change (McCrae \& Costa 1997). Meta-analytic results demonstrated that Openness is consistently associated with training proficiency and engaging in learning experiences (Barrick, Mount, \& Judge, 2001). Devaraj et al. (2008) found that there is a significant and positive relationship between Openness and intention to use technology.

In a study conducted by The, Yong, Chong, and Yew (2011), university students with higher levels of Openness to experience have a less favorable attitude towards online entertainment knowledge sharing. However, McElroy Hendrickson, Townsend, and DeMarie (2007) found that Openness is a significant predictor of general Internet use. They suggested that open individuals are more likely to use the Internet. This finding is in line with Tuten \& Bosnjak (2001), who found that open people are attracted to online activity to sate their curiosity and seek out new forms of adventure. Jacques et al. (2009) found Openness to positively correlate with intention to use virtual reality teams, which is mediated by technology communication anxiety. Lauriola and Levin (2001) found that subjects who scored high on Openness were more likely to take risk to achieve a gain.

The Komarraju and Karau (2005) study yielded three particularly strong underlying academic motives: avoidance, engagement, and achievement. Avoidant students tend to feel discouraged about school, worry about failure, withdraw in the classroom, and take courses for extrinsic reasons. In contrast, engaged students enjoy the process of learning, seek knowledge for selfimprovement, and enjoy sharing ideas (intrinsic motivation), while, achievement oriented students put in effort to excel and enjoy outperforming others (extrinsic motivation). Students with higher levels of Openness and Extraversion were more engaged in learning, with Openness explaining the most variance. This suggests that students who are sociable and enjoy exposure to new ideas are likely to be engaged in the educational experiences and may benefit from discussion and interactive learning.

H7. Openness has a significantly positive and direct effect on Perceived Enjoyment.

Students who were more conscientious, neurotic, and open to experience (Openness) scored higher on achievement (extrinsic motivation) with Conscientiousness explaining the most variance. These results suggest that students who are responsible and intellectually curious may be more achievement oriented, hard-working, and competitive.

H8. Openness has a significantly positive and direct effect on Perceived Usefulness. 
The SEM analysis by Devaraj et al. (2008) indicated a statistically significant and positive relationship between Openness and intention to use technology. Devaraj et al. (2008) state that, despite initial TRA-based work that presented personality as an external variable that might affect intention to use only through usefulness and ease-of-use, the research found evidence that certain aspects of personality might have a more direct impact on intention to use technology as well.

H9. Openness has a significantly positive and direct effect on Behavioral Intention.

\section{Extraversion (EX)}

Extraversion is the degree to which an individual is talkative, full of energy, and emotionally expressive (John \& Srivastava, 1999). Those high in Extraversion are social, active, and outgoing, and place a high value on close and warm interpersonal relationships (Watson \& Clark, 1997). Extraverts are more interested in the quantity rather than the quality of relationships, resulting in an individual being more willing to trust in order to attain more and more relationships to satisfy his/her need for interpersonal interactions (Jacques et al., 2009).

Wang et al. (2010) found Extraversion to have a direct positive effect on Perceived Enjoyment of blogging and an indirect positive effect on behavioral intention to blog which is in line with the work of Amichai-Hamburger and Ben-Artzi (2003), who found that Extraversion was positively associated with the use of either information or leisure services in the Internet. Extrovert university students who are sociable are more likely to share online entertainment knowledge in order to seek company and desired excitement (Teh et al., 2011).

Komarraju and Karau (2005) found that students with higher levels of Openness and Extraversion were more engaged (intrinsically motivated) in learning. This suggests that students who are sociable and enjoy exposure to new ideas are likely to be engaged in the educational experience and may benefit from discussion and interactive learning. It is interesting to note that sociability may lead students to be both more involved in the learning processes and more concerned with social and economic consequences of learning.

H10. Extraversion has a significantly positive and direct effect on Perceived Enjoyment.

Devaraj et al. (2008) found statistical support for the important role of Extraversion in moderating the relationship between Subjective Norms and intention to use technology, such that, the relationship is stronger for extroverts.

H11. Extraversion has a significantly positive and direct effect on Subjective Norms.

\section{Neuroticism (NE)}

The thought of using new technology or familiar technology in new ways makes the neurotic individual avoid such situations where there is uncertainty in outcomes (Jacques et al., 2009). Jacques et al. (2009) found Neuroticism to negatively correlate with Intention to use virtual reality teams, which is mediated by technology communication anxiety. Lauriola and Levin (2001) found that subjects who scored high on Neuroticism were less likely to take risk to achieve a gain however Neuroticism positively weighed on risk-taking to avoid a loss and was very close to statistical significance when controlling for demographics.

It was found by Devaraj et al. (2008) that Neuroticism is negatively associated with beliefs about the Perceived Usefulness of technology. Neuroticism is reflected in a negative reaction to both life and work situations, and this will generalize to beliefs about the perceived usefulness of technology. Neurotic personalities are likely to view technological advances in their work as threatening and stressful and to have generally negative thought processes when considering technological advances (Devaraj et al., 2008). 
Komarraju and Karau (2005) found that avoidance (an academic motive) was positively related with both Neuroticism and Extraversion, with Neuroticism explaining the most variance. These results may suggest that neurotic students tend to avoid many aspects of academic life and view education as a means to an end rather than an intrinsically fulfilling enterprise. However students who were more Conscientious, Neurotic, and open to experience scored higher on achievement (an academic motive) with Conscientiousness explaining the most variance. When viewed along with the fact that Neuroticism positively weighed on risk-taking to avoid a loss (Lauriola \& Levin, 2001), we draw the conclusion that neurotic individuals will engage in an activity when they are challenged.

McElroy et al. (2007) found that Neuroticism is a strong predictor of e-selling, which adds to the explanation for Internet use variance, even though, it is just below the conventional standard of statistical significance. Seeking information, socializing, and selling goods online may enable neurotic people to escape the stress of face-to-face interaction (McElroy et al., 2007). This finding is in line with Amiel \& Sargent (2004), which states that neurotic people spend extensive time on the Internet seeking to gain a sense of belonging.

Teh et al. (2011) found that university students with higher levels of Neuroticism have a more favorable attitude towards online entertainment knowledge sharing. One explanation provided for this finding is that the Internet provides a platform for the neurotic students to feel secure enough to share online entertainment knowledge and socialize with other members in order to improve their emotional stability. This is also consistent with Amichai-Hamburger and Ben-Artzi (2000), in which, Neuroticism was positively related to the use of social services (e.g., chatting and participating in forums) on the Internet. Similarly, Guadagno, Okdie, and Eno (2008) found that people who are high in Neuroticism are likely to be bloggers who express personal content using a blog, a new form of online self-presentation and self-expression.

A neurotic individual might see eLearning as an opportunity to avoid social interactions that he/she might have to engage in a traditional classroom situation. They would find eLearning useful for learning, interacting, discussing, and expressing themselves without going through the experience of face-to-face communication and interaction.

H12. Neuroticism has a significantly positive direct effect on Perceived Usefulness.

\section{Agreeableness (AG)}

Agreeableness is the degree to which an individual is helpful and unselfish with others, has a forgiving nature, and is generally trusting. Agreeable individuals tend to get along well with a variety of others and tend to trust others more quickly (Jacques et al., 2009). Agreeableness represents a person's sensitivity to and consideration toward the thoughts and opinions of others (Devaraj et al., 2008).

The agreeable personality is described as being kind, considerate, likable, helpful, and cooperative (Graziano \& Eisenberg, 1997). Agreeableness is the degree to which an individual is helpful and unselfish with others, has a forgiving nature, and is generally trusting (John \& Srivastava, 1999). Meta-analytic results suggest that Agreeableness has significant predictive validity in jobs involving considerable interpersonal interaction and teamwork, especially when the interaction involves helping and cooperating with others (Barrick et al., 2001). Farsides and Woodfield (2003) state that Agreeableness was the only personality trait to be positively associated with the verbal IQ measure, and if one had to pick a single proxy for a combination of intelligence and motivation it would probably be Agreeableness. Agreeableness was observed to be a direct antecedent of Perceived Enjoyment, and an indirect determinant of blogging intention (Wang et al., 2010).

H13. Agreeableness has a significantly positive and direct effect on Perceived Enjoyment. 
Devaraj et al. (2008) found support for Agreeableness being positively associated with beliefs about the Perceived Usefulness of technology. Agreeable personalities are more likely to be accommodating and cooperative when asked to consider a new technology, and to focus more on positive and cooperative dimensions of the technology rather than those elements that may be less facilitative of performance (Devaraj et al., 2008).

H14. Agreeableness has a significantly positive and direct effect on Perceived Usefulness.

Social influence has been shown to play an important role in the technology acceptance process (Malhotra \& Galletta, 2005; Venkatesh \& Morris, 2000). Image is another social influence concept which refers to the extent to which an innovation is perceived as enhancing one's status in a social system (Moore \& Bensbasat, 1991; Venkatesh \& Davis, 2000). Both Subjective Norms and image are important determinants of behavioral intention because they reflect the influence of others and the importance of having others to think positively of us (Devaraj et al., 2008).

Devaraj et al. (2008) found support for Agreeableness moderating the relationship between Subjective Norms and intentions to use the technology such that the relationship is stronger for individuals with higher Agreeableness.

H15. Agreeableness has a significantly positive and direct effect on Subjective Norms.

\section{Conscientiousness (CS)}

The conscientious individual finds it more difficult to trust in others in a team environment for fear of other people's unreliable behavior reflecting on him/her. The conscientious individual prefers to work alone when he/she knows that his/her outcomes will be evaluated by others (Jacques et al., 2009). People with a highly conscientious personality will be more likely to carefully consider ways in which the use of technology will allow them to be more efficient and perform at a higher level at work. If this processing results in positive beliefs about the technology - that the technology will facilitate effective job performance - then, Conscientiousness will magnify those beliefs and increase behavioral intentions (Devaraj et al., 2008). Landers and Lounsbury (2004) found that Conscientiousness was positively associated with relative Internet usage for academic purposes, but negatively associated with relative Internet usage for leisure functions. Wang et al. (2010) found Conscientiousness to have a significant negative influence on Perceived Enjoyment, which in turn was a determinant of blogging intention.

H16. Conscientiousness has a significantly negative and direct effect on Perceived Enjoyment.

Devaraj et al. (2008) observed support for Conscientiousness moderating the relationship between Perceived Usefulness of technology and intentions to use the technology such that the relationship is stronger for individuals with higher Conscientiousness. A conscientious individual might find the conveniences of eLearning such as time saving, flexible learning, and lone learning useful.

H17. Conscientiousness has a significantly positive and direct effect on Perceived Usefulness.

Conscientious people are intrinsically motivated to succeed, therefore they will carefully consider and weigh the opinions of trustworthy others as they consider whether or not to use a new technology. If conscientious personalities think that significant others believe that the technology should be used, they will form stronger intentions to use the technology (Devaraj et al., 2008).

H18. Conscientiousness has a significantly positive and direct effect on Subjective Norms.

\section{Computer Self-Efficacy (CSE)}

The TAM perspective focuses almost exclusively on beliefs about the technology and the outcomes of using it, whereas Social Cognitive Theory (SCT) includes other beliefs that might influ- 
ence behavior, independent of perceived outcomes. Self-efficacy is the belief that one has the capability to perform a particular behavior, and it is an important concept in SCT (Gong et al., 2004).

Computer Self-Efficacy refers to individuals' judgment of their capabilities to use computers in diverse situations (Compeau \& Higgins, 1995). Previous IT acceptance research results have confirmed the critical role that Computer Self-Efficacy plays in understanding individual responses to information technology (Agarwal, Sambamurthy, \& Stair, 2000; Chau, 2001; Igbaria \& Iivari, 1995; Johnson, \& and Marakas, 2000).

Individuals with a weak sense of Computer Self-Efficacy will be frustrated more easily by obstacles to their performance and will respond by lowering their perceptions of their capability of using a computer or information technology. Conversely, individuals with a strong sense of Computer Self-Efficacy will not be deterred easily by difficult problems and will persist with their efforts, with the result that they are more likely to overcome whatever obstacle that they confront (Compeau \& Higgins, 1995). Gong et al. (2004) found that Computer Self-Efficacy showed strong positive effect on Perceived Ease of Use about web-based learning systems.

H19. Computer Self-Efficacy has a significantly positive and direct effect on Perceived Ease of Use.

\section{Theoretical Model}

Based on prior studies the model shown in Figure 2 was developed. The model includes six exogenous independent variables belonging to the Individual Differences category, four mediating variables belonging to the belief category, and finally the dependent endogenous variable, Behavioral Intention. Each of the 11 variables is a latent variable measured with more than one indicator as described in Table 1. All of the research hypotheses identified in the literature review are noted as causal relationships among the variables in the model. It is not claimed that all possible variables or causes and effects are included in the proposed theoretical model but as shown in the literature review there is a strong theoretical support for the variables and cause and effect relationships that are included in the model.

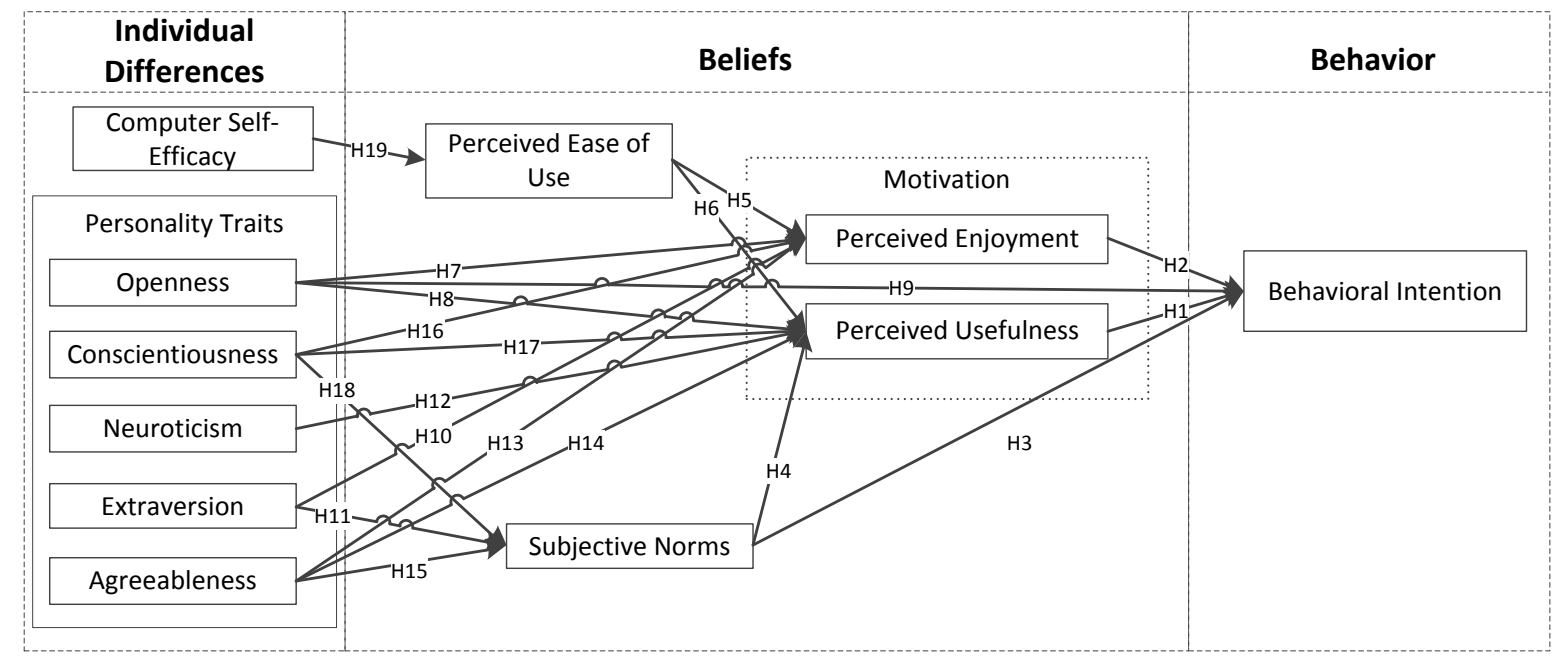

Figure 2: Theoretical Model

All of the model variables in Figure 2 are latent variables measured with the indicators and measuring instruments shown in Table 1. Each indicator is measured on a 5 point Likert scale and the measures are treated as interval scale measures in analyses. 
Table 1: Indicators and measuring instruments for latent model variables

\begin{tabular}{|l|l|l|l|l|l|}
\hline Variable (Symbol) & \multicolumn{1}{|c|}{ Indicators } & $\begin{array}{l}\text { Existing } \\
\text { Measuring } \\
\text { Instrument }\end{array}$ & Variable (Symbol) & Indicators & $\begin{array}{l}\text { Existing } \\
\text { Measuring } \\
\text { Instrument }\end{array}$ \\
\hline $\begin{array}{l}\text { Computer Self- } \\
\text { Efficacy (CSE) }\end{array}$ & CSE1- CSE10 & $\begin{array}{l}\text { Gong et al., } \\
2005\end{array}$ & Extraversion (EX) & EX1-EX7 & $\begin{array}{l}\text { Teh et al., } \\
2011\end{array}$ \\
\hline $\begin{array}{l}\text { Perceived Ease of } \\
\text { Use (PEU) }\end{array}$ & PEU1- PEU6 & $\begin{array}{l}\text { Gong et al., } \\
2005\end{array}$ & $\begin{array}{l}\text { Conscientiousness } \\
\text { (CS) }\end{array}$ & CS1-CS9 & $\begin{array}{l}\text { Teh et al., } \\
2011\end{array}$ \\
\hline $\begin{array}{l}\text { Perceived Useful- } \\
\text { ness (PU) }\end{array}$ & PU1- PU6 & $\begin{array}{l}\text { Gong et al., } \\
2005\end{array}$ & Agreeableness (AG) & AG1-AG8 & $\begin{array}{l}\text { Teh et al., } \\
2011\end{array}$ \\
\hline $\begin{array}{l}\text { Perceived Enjoy- } \\
\text { ment (PE) }\end{array}$ & PE1- PE3 & $\begin{array}{l}\text { Fagan et al., } \\
2008\end{array}$ & Openness (OP) & OP1-OP7 & $\begin{array}{l}\text { Teh et al., } \\
2011\end{array}$ \\
\hline $\begin{array}{l}\text { Behavioural Inten- } \\
\text { tion (BI) }\end{array}$ & BI1- BI6 & $\begin{array}{l}\text { Gong et al., } \\
2005\end{array}$ & Neuroticism (NE) & NE1-NE7 & $\begin{array}{l}\text { Teh et al., } \\
2011\end{array}$ \\
\hline $\begin{array}{l}\text { Subjective Norms } \\
\text { (SN) }\end{array}$ & SN1-SN4 & $\begin{array}{l}\text { Teh et al., } \\
2011\end{array}$ & & & \\
\hline
\end{tabular}

\section{Data Preparation and Preliminary Data Analysis}

\section{Data Preparation}

The data from the 249 returned questionnaires were imported into a statistical work sheet (SPSS) and a random 10 percent (25) were checked for accuracy of data entry and no errors were found. No missing values for any of the model variables were found as the questionnaire system enforced the answering of all questions before it could be submitted. No questionnaires had to be removed from the sample because there were no outliers (i.e., 3 or more standard deviations from the mean). Consequently, the final sample size of 249 satisfied the minimum sample size of 240 determined for the study.

Principle component factor analysis was used to evaluate the construct (convergent and discriminant) validity of the measures of the indicators for the latent model variables and Cronbach alpha coefficients were used to examine their equivalence reliability. The results of these analysis in Appendix Tables A1 and A2 show a final set of indicators for each latent variable with satisfactory construct validity (i.e., indicators which have a loading of magnitude 0.4 or greater only on their associated latent variable with an eigenvalue of 1 or more (Straub, Boudreau, \& Gefen, 2004)). The only indicators removed due to cross loading were PU5 and PU6 for Perceived Usefulness. They were cross loading on to Perceived Ease of Use (PEU). The internal consistency reliability (equivalence reliability) of the indicators resulting from the factor analysis was determined using Cronbach alpha coefficients (i.e. indicators with a Cronbach alpha coefficient of at least 0.7 (George \& Mallery, 2003)) and the results shown in Appendix Table A3.

\section{Descriptive Statistics for Model Variables}

The mean, standard deviation, skewness, and kurtosis for the model variables are displayed in Appendix Table A4. In addition to determining these statistics for the indicators of the latent variables, they were determined for each latent variable using a single measure for each latent variable that was determined for each respondent by finding the mean value they assigned to the indicators for the latent variable. Based on the very acceptable construct validity and alpha coefficients for the latent variables, the single scale measures for the latent variables were considered to be good representations of these variables for the purpose of the descriptive analyses.

It is noted from Appendix Table A4 that the magnitudes of skewness and kurtosis are within the acceptable limits of 3 and 7, respectively, recommended by Kline (2005) for the use of maximum 
likelihood estimation in the subsequent SEM analyses. In particular, it is noted that measures for Neuroticism (NE) from the questionnaire are such that the larger the value of this variable the less the individual displays the negative characteristics associated with neuroticism. This interpretation of the measures of NE must be noted throughout the interpretation of the results of analyses presented in this study.

Appendix Table A5 presents the correlation coefficients for the associations among the model variables. The highlighted coefficients are statistically significant at a level of 0.05 (2-tail). It is noted that all of the six exogenous variables (EX, AG, CS, NE, OP, and CSE) have significant correlations with each other. The shaded cells (Table A5) represent 17 significant positive correlations each of which is associated with a proposed direct significant causal effect in the theoretical model. Although these significant correlations do not establish significant causal effects they do suggest that these effects may be significant when tested in the SEM analyses. However, it is seen that the two significant direct effects $\mathrm{CS} \rightarrow \mathrm{PE}$ and $\mathrm{AG} \rightarrow \mathrm{PE}$, which are included in the theoretical model, are not associated with significant correlations shown in Appendix Table A5. This suggests that these causal effects may not be significant when tested in the SEM analyses. There are also 14 significant correlations between variables that are not represented by direct causal effects in the theoretical model. Taking into account of the temporal condition that $\mathrm{A} \rightarrow \mathrm{B}$ means that A precedes B in time it is plausible that 12 of the 14 correlations may be associated with additional causal effects that may be included in the model. These possible 12 additional causal effects are shown in Table 2 .

Table 2: Possible additional causal effects

\begin{tabular}{|l|l|}
\hline \multicolumn{1}{|c|}{ Possible Additional Effects } & \multicolumn{1}{c|}{ Possible Additional Effects } \\
\hline $\mathrm{EX} \rightarrow \mathrm{PU}$ & $\mathrm{CSE} \rightarrow \mathrm{PE}$ \\
$\mathrm{EX} \rightarrow \mathrm{PEU}$ & $\mathrm{CSE} \rightarrow \mathrm{BI}$ \\
\cline { 2 - 2 } $\mathrm{EX} \rightarrow \mathrm{BI}$ & $\mathrm{AG} \rightarrow \mathrm{BI}$ \\
\hline $\mathrm{NE} \rightarrow \mathrm{PEU}$ & $\mathrm{CS} \rightarrow \mathrm{BI}$ \\
\cline { 2 - 2 } $\mathrm{NE} \rightarrow \mathrm{SN}$ & $\mathrm{PEU} \rightarrow \mathrm{BI}$ \\
\cline { 2 - 2 } $\mathrm{NE} \rightarrow \mathrm{BI}$ & $\mathrm{PE} \rightarrow \mathrm{PU}$ \\
\hline
\end{tabular}

\section{Profile of Respondents}

The respondents represented 26 different countries with the majority of the respondents ( 83 percent) residing in Thailand during their study. Most of the respondents (67 percent) had no prior experience with eLearning and most of those with no prior experience (64 percent) were females. Comparison of gender against prior experience with eLearning is shown in Table 3. In relation to the model variables, where there were significant differences between males and females, on average females were found to be more agreeable in nature than males but compared to the females the males enjoyed eLearning more, were less neurotic, were more open, had better computer skills, and expressed stronger intentions to use eLearning in the future. Compared to respondents without prior eLearning experience, those who had prior experience were on average less neurotic, more open, had better computer skills, and stronger intentions to use eLearning in the future. It is interesting to observe that there were more female respondents actually engaging in eLearning without any prior experience than males.

Table 3: Comparison of gender with previous experience with eLearning

\begin{tabular}{|c|c|c|c|}
\hline \multirow{2}{*}{ Gender } & \multicolumn{2}{|c|}{ Previous Experience with eLearning } & \multirow{2}{*}{ Total } \\
\hline & Experienced & Not Experienced & \\
\hline Female & 31 & 107 & 138 \\
\hline Male & 50 & 61 & 111 \\
\hline Total & 81 & 168 & 249 \\
\hline
\end{tabular}


Each model variable was measured on a 5-point Likert scale ranging from 1 to 5 . The value of 3 represents a point on the scale where the respondent has a neutral response to the construct represented by the variable and 5 represents a very strong response to the construct represented by the variable. T-tests were conducted to determine the model variables with means that are significantly different from 3 and 5, respectively. It was found that all of the means for the model variables are significantly greater than the neutral value of 3 and all of the means for the model variables are significantly less than 5 at a level of significance of 0.05 .

There is a statistically significant difference between the means for males and females especially for the six variables, Perceived Enjoyment, Agreeableness, Neuroticism, Openness, Computer Self-Efficacy and Behavioral Intention. For each of these six variables the mean value for males is significantly greater than the mean value for females with the exception of Agreeableness where the females are significantly more agreeable than the males.

The comparison of respondents with and without prior eLearning experience show that those respondents with prior experience have a significantly higher mean value for each of the four variables, Neuroticism, Openness, Computer Self-Efficacy, and Behavioral Intention. This suggests that those with good computer systems skills who are open to new experiences and show few signs of neuroticism act on their strong intentions to engage in further eLearning experiences.

\section{Model Analysis and Development}

The Structural Equation Modelling (SEM) analysis is used to answer research question 3, among the factors and relationships that affect an individual's intention to study in an eLearning mode, which factors are the most important and which are the significant causal relationships. SEM is a statistical technique for testing and estimating causal (cause-effect) relations using a combination of statistical data and qualitative causal assumptions. A causal model is an abstract model that describes the causal mechanisms of a system. The model must express more than correlation because correlation does not imply causation. All of the analysis and development of causal models in this study used SEM techniques implemented with the AMOS 18 computer software following the guidance provided by Kline (2005).

Table 4 shows the results of SEM analysis of the direct effects in the theoretical model. It can be seen from the Table 4 that there are seven (bolded) small direct effects that are not statistically significant at a level of 0.05 or less.

Table 4: SEM analysis of the direct effects in the theoretical model

\begin{tabular}{|l|c|c|c|c|}
\hline \multicolumn{1}{|c|}{ Effect } & $\begin{array}{c}\text { Unstandardized } \\
\text { Estimate of Effect }\end{array}$ & $\begin{array}{c}\text { Statistical Significance of } \\
\text { Unstandardized } \\
\text { Estimate of Effect }\end{array}$ & $\begin{array}{c}\text { Standardized Es- } \\
\text { timate of Effect }\end{array}$ & $\begin{array}{c}\text { Magnitude of } \\
\text { Standardized Es- } \\
\text { timate of Effect }\end{array}$ \\
\hline $\mathrm{CSE} \rightarrow \mathrm{PEU}$ & .351 & $* * *$ & .394 & Medium \\
\hline $\mathrm{EX} \rightarrow \mathrm{SN}$ & .147 & .148 & .114 & Medium \\
\hline $\mathrm{CS} \rightarrow \mathrm{SN}$ & .155 & .198 & .114 & Medium \\
\hline $\mathrm{AG} \rightarrow \mathrm{SN}$ & .187 & .128 & .126 & Medium \\
\hline $\mathrm{PEU} \rightarrow \mathrm{PE}$ & .256 & $* * *$ & .223 & Medium \\
\hline $\mathrm{PEU} \rightarrow \mathrm{PU}$ & .632 & $* * *$ & .656 & Large \\
\hline $\mathrm{EX} \rightarrow \mathrm{PE}$ & .200 & $*$ & .161 & Medium \\
\hline $\mathrm{CS} \rightarrow \mathrm{PE}$ & -.245 & $*$ & -.186 & Medium \\
\hline $\mathbf{C S} \rightarrow \mathrm{PU}$ & .109 & .132 & .099 & Small \\
\hline $\mathrm{AG} \rightarrow \mathrm{PE}$ & .146 & .221 & .101 & Medium \\
\hline $\mathbf{A G ~} \rightarrow$ PU & -.008 & .916 & -.007 & Small \\
\hline $\mathrm{SN} \rightarrow \mathrm{PU}$ & .154 & $* * *$ & .189 & Medium \\
\hline
\end{tabular}




\begin{tabular}{|l|c|c|c|c|}
\hline \multicolumn{1}{|c|}{ Effect } & $\begin{array}{c}\text { Unstandardized } \\
\text { Estimate of Effect }\end{array}$ & $\begin{array}{c}\text { Statistical Significance of } \\
\text { Unstandardized } \\
\text { Estimate of Effect }\end{array}$ & $\begin{array}{c}\text { Standardized Es- } \\
\text { timate of Effect }\end{array}$ & $\begin{array}{c}\text { Magnitude of } \\
\text { Standardized Es- } \\
\text { timate of Effect }\end{array}$ \\
\hline $\mathbf{O P} \rightarrow \mathbf{P E}$ & .069 & .476 & .055 & Small \\
\hline $\mathbf{O P} \rightarrow \mathbf{P U}$ & .028 & .637 & .026 & Small \\
\hline $\mathbf{N E ~} \rightarrow \mathbf{P U}$ & -.032 & .570 & -.034 & Small \\
\hline $\mathbf{P E ~} \rightarrow \mathbf{B I}$ & .076 & .228 & .066 & Small \\
\hline $\mathrm{PU} \rightarrow \mathrm{BI}$ & .504 & $* * *$ & .365 & Medium \\
\hline $\mathrm{SN} \rightarrow \mathrm{BI}$ & .478 & $* * *$ & .425 & Medium \\
\hline $\mathbf{O P} \rightarrow \mathbf{B I}$ & .057 & .472 & .039 & Small \\
\hline
\end{tabular}

Note: *, **, and *** represent statistical significance at levels of $0.5,0.01$, and 0.001 , respectively.

Table 5 shows the values of the range of fit statistics recommended by Kline (2005) for the theoretical model. The values indicate that the fit statistics GFI, AGFI, NFI, IFI, and CFI are not very satisfactory. This suggests that the proposed model may be improved by further development. For this reason further development of the theoretical model is to be made to find a final model with an improved fit statistic.

Table 5: Fit statistics for the theoretical model

\begin{tabular}{|c|c|c|c|c|c|c|c|c|c|c|}
\hline Model & $\mathbf{N}$ & $\mathbf{N}_{\mathbf{c}}$ & $\mathbf{N C}\left(\boldsymbol{\chi}^{\mathbf{2}} / \mathbf{d f}\right)$ & $\mathbf{R M R}$ & $\mathbf{G F I}$ & AGFI & NFI & IFI & CFI & RMSEA \\
\hline $\begin{array}{c}\text { Theoretical } \\
\text { Model }\end{array}$ & 249 & 153 & $\begin{array}{c}4053.077 / 2380= \\
1.703\end{array}$ & 0.041 & 0.694 & 0.671 & 0.778 & 0.895 & 0.894 & 0.053 \\
\hline \multicolumn{8}{|c|}{$\mathrm{R}^{2}: 0.381$ for SN, 0.356 for PEU, 0.385 for PE, 0.511 for PU, and 0.414 for BI. } \\
\hline
\end{tabular}

Note: $\mathrm{R}^{2}$ is the proportion of the variance for each endogenous variable that is explained by the causes.

The 12 direct effects shown in Table 2 and the seven small and not statistically significant effects in Table 4 (SEM analysis of the direct effects in the theoretical model) were made optional effects in the theoretical model and the resulting hierarchy of $2^{19}=524,288$ models was analyzed using the specification search facility in AMOS. Following the recommendation of Kline (2005) among these models the one with the smallest value for NC (Normed Chi-square) was selected as the final model which is shown in Figure 3 with the fit statistics in Table 6.

Table 6: Fit statistics for the final model

\begin{tabular}{|c|c|c|c|c|c|c|c|c|c|c|}
\hline Model & $\mathbf{N}$ & $\mathbf{N}_{\mathbf{c}}$ & $\mathbf{N C}\left(\boldsymbol{\chi}^{\mathbf{2} / \mathbf{d f})}\right.$ & $\mathbf{R M R}$ & GFI & AGFI & $\mathbf{N F I}$ & IFI & CFI & RMSEA \\
\hline $\begin{array}{c}\text { Final } \\
\text { Model }\end{array}$ & 249 & 153 & $\begin{array}{c}2427.312 / 1464= \\
1.658\end{array}$ & 0.038 & 0.924 & 0.910 & 0.911 & 0.914 & 0.914 & 0.035 \\
\hline
\end{tabular}

$\mathrm{R}^{2}: 0.488$ for SN, 0.378 for PEU, 0.433 for PE, 0.595 for PU, and 0.580 for BI.

Note: $\mathrm{R}^{2}$ is the proportion of the variance for each endogenous variable that is explained by the causes.

Tables 5 and 6 provide evidence that the fit statistics of the final model are greatly improved compared to those for the theoretical model, and all of the direct effects are statistically significant at a level of 0.05 or less.

From Figure 3, it is noted that the final model does not include the two variables AG (Agreeableness) and (OP) Openness and several direct effects in the theoretical model are not included. The final model includes the statistically significant but small direct effect CS (Conscientiousness) $\rightarrow$ PU (Perceived Usefulness), if this small effect is deleted the fit statistics are less satisfactory. Also, very reasonable proportions (approximately $38-60$ percent) of the variance of the endogenous variables are explained by their causes. A direct effect from PE (Perceived Enjoyment) to BI (Behavioral Intention) is not significant in the final model which has the smallest value for NC. 
Consequently, PE (Perceived Enjoyment) is considered to be a second dependent variable in addition to BI (Behavioral Intention) in the final model.

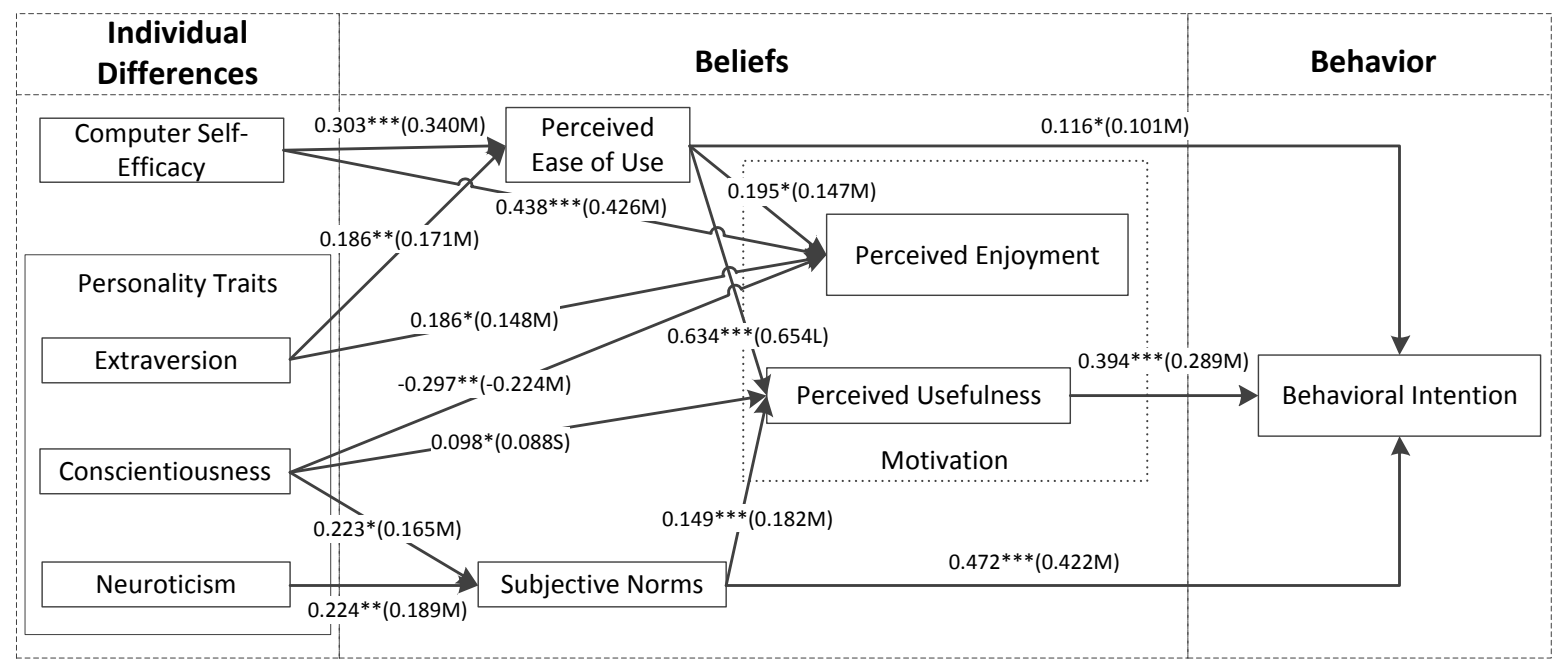

Figure 3: Final model.

The full details of all of effects in the final model are shown in Appendix Table A6 using the same format as in Figure 3 and variables on indirect paths are labeled. The determination of the statistical significance of effects and an interpretation of their magnitudes used the methods proposed by Sobel (1986), Cohen \& Cohen (1983) and Cohen (1988). The notations *, **, or *** are used with unstandardized effects to indicate statistical significance at a level of $0.05,0.01$, or 0.001 , respectively. Standardized effects are shown in parentheses with magnitudes classified as small (S), medium (M), or large (L) (Cohen, 1988).

\section{Discussion}

Table 7 shows the summary of the results of the 19 hypotheses that were tested. Only one hypothesis failed to find any support at all. The rest of the 18 hypotheses were either fully or partially supported. The findings are further discussed in the discussion section below.

Table 7: Summary of the results of hypothesis testing.

\begin{tabular}{|l|l|c|l|}
\hline \multicolumn{2}{|l|}{ Hypothesis } & Supported & \multicolumn{1}{|c|}{ Reference } \\
\hline H1 & $\begin{array}{l}\text { Perceived Usefulness has a significant positive and direct } \\
\text { effect on Behavioral Intention. }\end{array}$ & Yes & $\begin{array}{l}\text { Lee et al., 2005; } \\
\text { Wang, et al., 2010) }\end{array}$ \\
\hline H2 & $\begin{array}{l}\text { Perceived Enjoyment has a significant positive direct effect } \\
\text { on Behavioral Intention. }\end{array}$ & Partially & Lee et al., 2005 \\
\hline H3 & $\begin{array}{l}\text { Subjective Norms has a significant positive direct effect on } \\
\text { Behavioral Intention. }\end{array}$ & Yes & $\begin{array}{l}\text { Devaraj et al., 2008; } \\
\text { Teh, et al., 2011; } \\
\text { Schepers \& Wetzel, } \\
\text { 2007 }\end{array}$ \\
\hline H4 & $\begin{array}{l}\text { Subjective Norms has a significant positive direct effect on } \\
\text { Perceived Usefulness. }\end{array}$ & Yes & $\begin{array}{l}\text { Schepers \& Wetzel, } \\
\text { 2007 }\end{array}$ \\
\hline H5 & $\begin{array}{l}\text { Perceived Ease of Use has a significant positive direct effect } \\
\text { on Perceived Enjoyment. }\end{array}$ & Yes & Lee et al., 2005 \\
\hline H6 & $\begin{array}{l}\text { Perceived Ease of Use has a significant positive direct effect } \\
\text { on Perceived Usefulness. }\end{array}$ & Yes & Lee et al., 2005 \\
\hline H7 & $\begin{array}{l}\text { Openness has a significant positive direct effect on Perceived } \\
\text { Enjoyment. }\end{array}$ & Partially & $\begin{array}{l}\text { Komarraju \& } \\
\text { Karau, 2005 }\end{array}$ \\
\hline
\end{tabular}




\begin{tabular}{|c|l|c|l|}
\hline H8 & $\begin{array}{l}\text { Openness has a significant positive direct effect on Perceived } \\
\text { Usefulness. }\end{array}$ & Partially & $\begin{array}{l}\text { Komarraju \& } \\
\text { Karau, 2005 }\end{array}$ \\
\hline H9 & $\begin{array}{l}\text { Openness has a significant positive direct effect on Behav- } \\
\text { ioral Intention. }\end{array}$ & Partially & Devaraj et al., 2008 \\
\hline H10 & $\begin{array}{l}\text { Extraversion has a significant positive direct effect on Per- } \\
\text { ceived Enjoyment. }\end{array}$ & Yes & $\begin{array}{l}\text { Wang et al. 2010; } \\
\text { Komarraju \& } \\
\text { Karau, 2005 }\end{array}$ \\
\hline H11 & $\begin{array}{l}\text { Extraversion has a significant positive direct effect on Sub- } \\
\text { jective Norms. }\end{array}$ & Partially & Devaraj et al., 2008 \\
\hline H12 & $\begin{array}{l}\text { Neuroticism has a significant positive direct effect on Per- } \\
\text { ceived Usefulness. }\end{array}$ & Partially & $\begin{array}{l}\text { Teh et al., 2011; } \\
\text { Komarraju \& } \\
\text { Karau, 2005 }\end{array}$ \\
\hline H13 & $\begin{array}{l}\text { Agreeableness has a significant positive direct effect on Per- } \\
\text { ceived Enjoyment. }\end{array}$ & No & Wang et al., 2010 \\
\hline H14 & $\begin{array}{l}\text { Agreeableness has a significant positive direct effect on Per- } \\
\text { ceived Usefulness. }\end{array}$ & Partially & Devaraj et al., 2008 \\
\hline H15 & $\begin{array}{l}\text { Agreeableness has a significant positive direct effect on Sub- } \\
\text { jective Norms. }\end{array}$ & Partially & Devaraj et al., 2008 \\
\hline H16 & $\begin{array}{l}\text { Conscientiousness has a significant negative direct effect on } \\
\text { Perceived Enjoyment. }\end{array}$ & Yes & Wang et al., 2010 \\
\hline H17 & $\begin{array}{l}\text { Conscientiousness has a significant positive direct effect on } \\
\text { Perceived Usefulness. }\end{array}$ & Yes & $\begin{array}{l}\text { Devaraj et al., 2008; } \\
\text { Komarraju \& } \\
\text { Karau, 2005 }\end{array}$ \\
\hline H18 & $\begin{array}{l}\text { Conscientiousness has a significant positive direct effect on } \\
\text { Subjective Norms. }\end{array}$ & Yes & Devaraj et al., 2008 \\
\hline H19 & $\begin{array}{l}\text { Computer Self-Efficacy has a significant positive direct ef- } \\
\text { fect on Perceived Ease of Use. }\end{array}$ & Yes & Gong et al., 2005 \\
\hline
\end{tabular}

\section{Interpretation of Causal Effects}

Table 8 shows the effects of exogenous variables on the intervening and the dependent variables, and the effect of intervening variables on dependent endogenous variables. It states if the relation is positive or negative, the magnitude of the relationship and if the effect is mainly direct or intervening.

Behavioral Intention to use eLearning as a mode of learning is strongest for individuals, in the following order of decreasing importance, who (1) perceive that people who are important to them think that they must engage in eLearning, (2) find eLearning to be easy to use and useful, and (3) believe that they have good computing skills. In terms of personality characteristics, intention to use eLearning is strongest for individuals, in the following order of decreasing importance, who (1) are responsible, reliable, hardworking and driven by the need for achievement, (2) are more emotionally stable, calm, and do not constantly experience negative feelings, and (3) are enthusiastic, talkative, assertive, and gregarious.

Perceptions that eLearning systems are easy to use and that friends and family agree with the use of eLearning have mainly direct effects on intentions to engage in eLearning while perceptions of the usefulness of eLearning have only a direct positive effect on intentions. The effects of personality traits and computer usage skills on intention are only indirect and positive. 
Table 8: Summary based on the total of effects in the final model

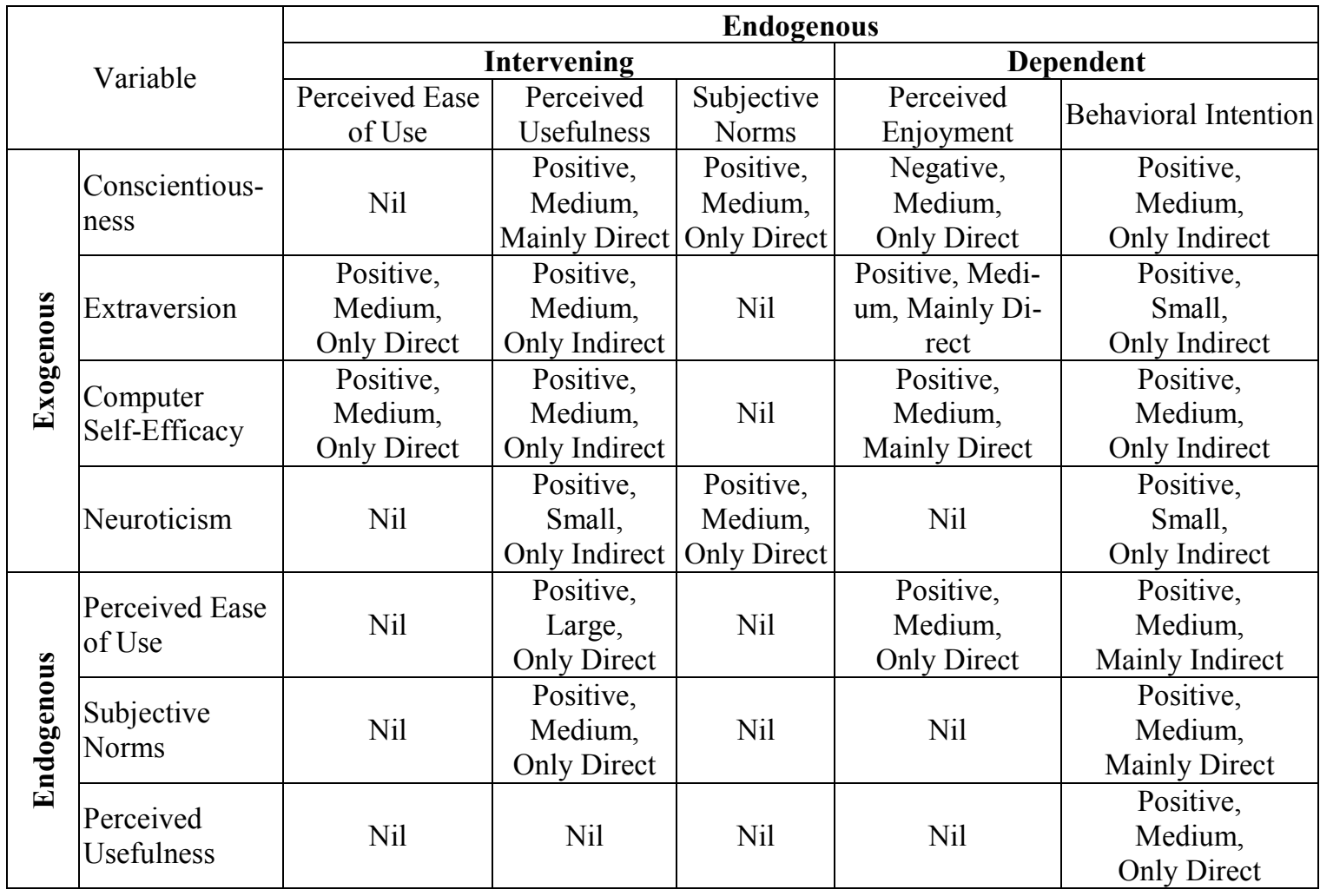

Perceived Enjoyment is the extent to which engaging in eLearning is perceived to be enjoyable, apart from any performance consequences. The perception that using eLearning systems is enjoyable is strongest for individuals, in the following order of decreasing importance, who (1) have the capability to use a computer, (2) consider eLearning as a means to an end, and (3) perceive the use of the eLearning system to be free of effort.

Interestingly, and as noted in previous studies the more organized, self-disciplined, and careful an individual is the less enjoyment they derive from using the eLearning system despite the outcome of its use. The perception that the eLearning system is easy to use as well as individual characteristics such as enthusiasm, assertiveness, and degree of socialization have a positive, medium, mainly direct effect on perception of enjoyment.

Perceived Usefulness is the degree to which an individual believes that using an eLearning system enhances their learning performance. This perception is strongest for individuals, in the following order of decreasing importance, who (1) perceive the eLearning system to be easy to use, (2) judge their computer skills to be good, (3) value the opinions and suggestions of those close to them, (4) are achievement oriented, careful, and thorough, (5) are talkative, energetic, and enthusiastic, and (6) are emotionally stable and less reactive to stress. The perception that the system is easy to use is the strongest determinant of the Perceived Usefulness of eLearning systems.

The only personality variable that exerts any direct effect of Perceived Usefulness is Conscientiousness and it is a direct positive, but small effect. The effects of Extraversion and Computer Self-Efficacy on Perceived Usefulness are mediated by the perception of the ease of use of the eLearning system and the effects are positive and medium. It is noted that the indirect effect of the variable Perceived Ease of Use on Behavioral Intention through the intervening variable Perceived Usefulness is greater in magnitude than the direct effect. This shows that Perceived Use- 
fulness has a significant mediating effect in the relationship between Perceived Ease of Use and Behavioral Intention.

Perceived Ease of Use is the degree to which a person believes that using the eLearning system would be free from effort. This perception is strongest for individuals, in the following order of decreasing importance, who (1) judge their computer skills as good and (2) are talkative, energetic, and enthusiastic. These effects are positive, medium, and direct.

Subjective Norms refers to an individual's perception that most people who are important to them think they should or should not engage in eLearning. The influences due to others is strongest for those who are dependable, organized, persevere, and are emotionally stable. These effects are positive, medium, and direct.

\section{Comparison with the Findings of Previous Studies}

As shown in Table 7 this study had found partial or full support for 18 of the research hypotheses that were derived from previous studies. Partially supported hypotheses are those for which significant direct causal effects were not found but had significant correlations between the variables in the same direction as that specified in the hypothesis. All of the eight hypotheses that were partially supported have a significant positive correlation. Two of the TAM relations tested (H1 and H6) were found to be significant as expected. All of the causal relationships hypothesized regarding the effect of Subjective Norms were fully supported by the findings and are in line with the findings of Schepers \& Wetzel (2007). The only hypothesis that has neither a causal effect nor a correlation is hypothesis H13. This contradicts the findings of Wang et al. (2010) that Agreeableness has a significant positive direct effect on Perceived Enjoyment. The only personality trait variable that found support for all the hypotheses (H16, H17, H18) proposed was Conscientiousness. For hypothesis H17, the direct effect is statistically significant though it has a small magnitude. Conscientiousness is the single variable that influences the largest number of belief variables.

\section{New Results Not Reported in Previous Studies}

Table 9 presents new findings which have not been reported in previous studies.

Table 9: New findings of direct significant medium effects

Computer Self-Efficacy has a significant positive, direct, medium effect on Perceived Enjoyment

Extraversion has a significant positive, direct, medium effect on Perceived Ease of Use

Neuroticism has a significant positive direct, medium, effect on Subjective Norms

Perceived Usefulness has a significant mediating effect in the relationship between Perceived

Ease of Use and Behavioral Intention.

In relation to the new findings in Table 9:

- The finding that individuals with well-developed computer skills find the use of the eLearning system to be enjoyable seems logical. Such individuals are likely to feel more comfortable and relaxed and thus find the use of the eLearning system to be enjoyable.

- As the degree of Extraversion of an individual increases so does their level of interaction, stimulation, and capacity for enjoyment. Consequently, it is not surprising that this enhances their perception that the eLearning system is easy to use.

- As the degree of Neuroticism decreases the level of an individual's adjustment and emotional stability increases, and it is not surprising that such individuals are likely to be in- 
creasingly receptive to the opinions of those close to them. This causal effect of Neuroticism on Subjective Norms was present in the theoretical model presented by Devaraj et al. (2008). However no hypothesis was developed or tested to explain this relationship.

\section{Implications of the Findings}

Theoretical implications of the study are summarized by the hypotheses which are fully or partially supported by the findings as well as hypotheses for which there was no support (see Table 7). In addition, the new findings (Table 9) present theoretical relationships that require further examination.

Table 10 describes practical objectives and associated actions derived from the final model. For each objective, the associated actions are ordered from the most effective first to the least effective last. Actions associated with small effects have not been included. Some actions are examined in more detail, as subsequent objectives, which appear later in the table.

Table 10: Objectives and actions to increase the intention to use eLearning

\begin{tabular}{|c|c|c|c|}
\hline Objective & Action & Comment & $\begin{array}{c}\text { Associated Model } \\
\text { Variable }\end{array}$ \\
\hline \multirow{5}{*}{$\begin{array}{l}\text { 1. Primary Objective: In- } \\
\text { crease intention to study } \\
\text { with eLearning }\end{array}$} & $\begin{array}{l}\text { 1. Increase positive perceptions of } \\
\text { eLearning among close associates of } \\
\text { potential students. }\end{array}$ & \begin{tabular}{|c|} 
See \\
Objective \\
2. \\
\end{tabular} & Subjective Norms \\
\hline & $\begin{array}{l}\text { 2. Increase perceptions that the tech- } \\
\text { nical system is easy to use. }\end{array}$ & \begin{tabular}{|c|} 
See \\
Objective \\
3. \\
\end{tabular} & $\begin{array}{c}\text { Perceived Ease of } \\
\text { Use }\end{array}$ \\
\hline & $\begin{array}{l}\text { 3. Increase perceptions that the tech- } \\
\text { nical system is useful for studying. }\end{array}$ & \begin{tabular}{|c|} 
See \\
Objective \\
4 \\
\end{tabular} & $\begin{array}{c}\text { Perceived Useful- } \\
\text { ness }\end{array}$ \\
\hline & $\begin{array}{l}\text { 4. Increase the individual's confi- } \\
\text { dence in their ability to use computer } \\
\text { technology in diverse situations. }\end{array}$ & - & $\begin{array}{l}\text { Computer Self- } \\
\text { Efficacy }\end{array}$ \\
\hline & $\begin{array}{l}\text { 5. Pay increased attention to promot- } \\
\text { ing eLearning to those who are orga- } \\
\text { nized, self-disciplined, and careful. }\end{array}$ & - & Conscientiousness \\
\hline \multirow{2}{*}{$\begin{array}{l}\text { 2. Increase positive percep- } \\
\text { tions of eLearning among } \\
\text { close associates of potential } \\
\text { students. }\end{array}$} & $\begin{array}{l}\text { 1. Pay increased attention to promot- } \\
\text { ing eLearning to those who are well } \\
\text { adjusted and emotionally stable. }\end{array}$ & - & Neuroticism \\
\hline & $\begin{array}{l}\text { 2. Pay increased attention to promot- } \\
\text { ing eLearning to those who are orga- } \\
\text { nized, self-disciplined, and careful. }\end{array}$ & - & Conscientiousness \\
\hline \multirow{2}{*}{$\begin{array}{l}\text { 3. Increase perceptions that } \\
\text { the technical system is easy } \\
\text { to use. }\end{array}$} & $\begin{array}{l}\text { 1. Increase the individual's confi- } \\
\text { dence in their ability to use computer } \\
\text { technology in diverse situations. }\end{array}$ & - & $\begin{array}{l}\text { Computer Self- } \\
\text { Efficacy }\end{array}$ \\
\hline & $\begin{array}{l}\text { 2. Pay increased attention to promot- } \\
\text { ing eLearning to those who are enthu- } \\
\text { siastic, energetic, fun loving, and en- } \\
\text { joy using computers. }\end{array}$ & 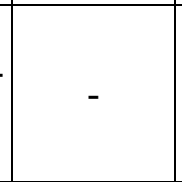 & Extraversion \\
\hline $\begin{array}{l}\text { 4. Increase perceptions that } \\
\text { the technical system is use- } \\
\text { ful for studying. }\end{array}$ & $\begin{array}{l}\text { 1. Increase perceptions that the tech- } \\
\text { nical system is easy to use. }\end{array}$ & $\mid \begin{array}{c}\text { See } \\
\text { Objective } \\
3\end{array}$ & $\begin{array}{l}\text { Perceived Ease of } \\
\text { Use }\end{array}$ \\
\hline
\end{tabular}




\begin{tabular}{|l|l|c|c|}
\hline Objective & \multicolumn{1}{|c|}{ Action } & Comment & $\begin{array}{c}\text { Associated Model } \\
\text { Variable }\end{array}$ \\
\hline & $\begin{array}{l}\text { 2. Increase the individual's confi- } \\
\text { dence in their ability to use computer } \\
\text { technology in diverse situations. }\end{array}$ & - & $\begin{array}{c}\text { Computer Self- } \\
\text { Efficacy }\end{array}$ \\
\hline & $\begin{array}{l}\text { 3. Increase positive perceptions of } \\
\text { eLearning among close associates of } \\
\text { potential eLearning students. }\end{array}$ & $\begin{array}{c}\text { See } \\
\text { Objective } \\
2\end{array}$ & Subjective Norms \\
\hline $\begin{array}{l}\text { 4. Pay increased attention to promot- } \\
\text { ing eLearning to those who are orga- } \\
\text { nized, self-disciplined, and careful. }\end{array}$ & - & Conscientiousness \\
\hline $\begin{array}{l}\text { 5. Pay increased attention to promot- } \\
\text { ing eLearning to those who are enthu- } \\
\text { siastic, energetic, fun loving, and en- } \\
\text { joy using computers. }\end{array}$ & - & Extraversion \\
\hline
\end{tabular}

Table 10 describes objectives and associated actions for the primary objective of increasing intentions to study with eLearning. A similar table may be constructed easily from the detailed results for the analysis of the final model but this has not been done since the dependent variable of primary concern was Behavioral Intention.

\section{Limitations of the Study}

The limitations of the study are identified in relation to the various forms of reliability and validity that apply to the measurement of constructs and the overall research design and results.

\section{Measurement reliability and validity}

Measurement Reliability refers to the dependability or consistency of the measurement of a variable. There are 3 types of measurement reliability: stability reliability, which examines the reliability of measures across time; representative reliability, which examines the reliability of measures across different groups of subjects; and equivalence reliability, which examines the internal consistency with which a set of indicators measure a latent variable (Neuman, 2006).

For stability and representative reliability no statistical analyses were used to assess these forms of measurement reliability, and this is normal for the cross-sectional research approach used in this study. However, wherever possible, existing measurements instruments reported in the literature were used to measure the variables, and these instruments have demonstrated both of these forms of reliability across studies conducted at different times, in different contexts, and with different subjects. Also, the responses in the pilot study were similar to those in the main survey. The assessment of equivalence (internal consistency) reliability used Cronbach's alpha coefficients. As reported earlier all of these coefficients were excellent.

Measurement Validity refers to how well an empirical indicator and the conceptual definition of the construct that the indicator is supposed to measure "fit" together. There are four main types of measurement validity: face validity, which considers how well the measurement of an indicator "makes sense" as a measure of the construct in the judgment of others; content validity, which examines how well the measures collected represent all the aspects of the conceptual definition of the construct; criterion validity (concurrent and predictive), which examines how well the measure of the indicator agrees with a preexisting measure and how well the measure predicts future events that are logically related to the construct being measured; and construct validity (conver- 
gent and discriminant), which examines how well a set of indicators for a construct measure that and only that construct (Neuman, 2006).

With regard to face validity and content validity, this study selected variables based on their importance in previous studies. Definitions of the variables from previous studies were used and existing measuring instruments were adopted that have been shown to produce measures that have satisfactory face and content validity. Also, a focus group was used to examine the variables included in the model, their definitions, their proposed relationships, and especially the questionnaire items designed to measure the variables. Actual measures for variables from previous studies were not available, and so the concurrent validity part of criterion validity was not assessed using statistical techniques and similarly no statistical assessment was made of the predictive validity part of criterion validity. However, there is evidence among the results of the analyses that the measures in the study have produced results that are in agreement with many of those reported in previous studies. The construct validity of the measures was assessed using factor analysis and this is explained in detail in Appendix Table A1. All of the latent model variables demonstrated satisfactory construct validity except for Perceived Usefulness (PU), where it was found that two of its indicators (PU5 and PU6) cross loaded significantly onto the variable Perceived Ease of Use and consequently these two indicators were removed from the set of indicators measuring Perceived Usefulness.

\section{Reliability and validity of the overall research design and results}

The Reliability of the Research Design used in the study and the results of the study can only be tested by other researchers repeating the study and this is strongly recommended.

The Internal Validity of the research design assesses whether there are errors internal to the design of the research project. It is used primarily in experimental research design to examine possible errors or alternative explanations of results that arise despite attempts to institute controls (Neuman, 2006). This study was a cross-sectional field study and the design does not allow controls to be introduced in the manner of experimental research. It was not proposed that all possible cause and effects were included in the theoretical model. Instead, the main variables and their associated causes and effects were derived from previous studies and formulated in a proposed theoretical model. Consequently, further studies may well examine other variables and causal effects which were not considered in this study and this is strongly recommended.

External Validity is used mainly in experimental research design and addresses the extent to which the findings may be generalized from a specific setting and group of subjects to other settings and groups (Neuman, 2006). This cross-sectional field study used a sample from the target population based on a 95 percent confidence level and a precision of 5 percent. Consequently, it is reasonable to conclude that the study will produce similar results to those obtained if it was repeated using other random samples of the same size and from the same target population.

Statistical Validity refers to the appropriate use of statistical techniques (Neuman, 2006). The statistical techniques used in this study are described above in the data analysis and model development sections. At first, preliminary analysis based on appropriate descriptive statistics was used. It addressed missing values, outliers, skewness, kurtosis, means, standard deviations, Principal Component factor analysis, Cronbach's alpha coefficients, t-tests, and correlation coefficients. These analyses were done using SPSS (version 19) software. Model development used Structural Equation Modelling (SEM) with maximum likelihood estimation implemented with the AMOS 18 software to test the proposed theoretical model in the form of a latent structured regression model and to evaluate modifications to that model in order to arrive at a final parsimonious model. As recommended by Kline (2005) the final model was selected from a hierarchy of 219 possible models based on the value of Normed Chi-square. A full analysis of the final model 
included the calculation of the statistical significance and an interpretation of the magnitude of all of the effects. All of the techniques were used appropriately in accordance with requirements and conditions specified in the literature.

\section{Future Research}

It has already been noted in the preceding sections that in order to establish the external validity of the results of this study, there is a need for the study to be repeated. Further studies need to be done to verify the findings of this study, especially the new findings. Also, the construct validity of two indicator variables of Perceived Usefulness (PU5 and PU6) need to be further investigated.

This research identified two dependent variables: Perceived Enjoyment and Behavioral Intention. It was found that in this study the model supported by the questionnaire data with the best fit statistics did not include an effect of Perceived Enjoyment on Behavioral Intention. This result was surprising and requires confirmation.

Since the majority of the respondents resided in Thailand during their course using eLearning, further studies need to sample a less geographically homogenous group. Cross cultural comparisons and longitudinal studies need to be conducted in order to examine possible changes over time and cultural effects on the relative importance of determinants of eLearning usage. The finding of Brahmasrene \& Lee (2012) that there is a significant difference between the U.S sample and the Korean sample regarding the perceived usefulness of online learning system adds weight to this. Also, the largest adopters of eLearning are corporations, which find it useful in keeping their workforce up to date. The determinants of behavioral intention to engage in eLearning for this purpose could be different from that of the more general educational sector. Saadé, Kira, and Nebebe (2012) found that cognitive traits significantly mediate the impact of perceived usefulness on attitudes while using online learning tool. Of course, there may be other variables that could be included in the theoretical model and extending the study of eLearning in that way is strongly recommended.

\section{Conclusion}

Out of the total 19 hypothesis proposed by this research, 10 were totally and 8 were partially supported. The unsupported hypothesis: the relationship between Agreeableness and Perceived Enjoyment is positive though not significant. This research has also confirmed that the effects of individual differences on behavior are mediated through beliefs despite the suggestion by Devaraj et al. (2008) that there might exist a positive relationship between Openness and Intention to use technology. Out of the five personality trait variables only three: Extraversion, Conscientiousness, and Neuroticism seems to have a significant predictive power in the final causal model. Conscientiousness is the personality trait that affects the widest range of beliefs, both positively and natively. Extraversion and Conscientiousness are the only personality variables influencing the original TAM variables when it comes to eLearning intention. It is important to note that Neuroticism is measured in such a manner that a person getting a high score on Neuroticism is actually low in Neuroticism and vice-versa. The surprising finding of this study is the fact that there does not exist a significant relationship between Perceived Enjoyment and Behavioral Intention to engage in eLearning despite that most prior research (e.g., Saade et al., 2008; Venkatesh et al., 2002; Wang et al., 2010) findings supported it. It could be assumed from this study that the primary determinants of eLearning usage at present are the extrinsic motivational factors such as Perceived Usefulness and Subjective Norms.

Compared to the females, the males enjoyed eLearning more, were less neurotic, were more open, had better computer skills, and expressed stronger intentions to use eLearning in the future. Compared to respondents without prior eLearning experience, those who had prior experience were on 
average less neurotic, more open, had better computer skills, and had stronger intentions to use eLearning in the future.

As the research had set out to do, it found some of the factors that determine an individual's behavioral intention to use eLearning. Organizations that have implemented eLearning or that are interested in implementing it can now be aware of some of the factors that determine the acceptance of eLearning. It was identified that social opinion about eLearning is a critical determinant that influences an individual's intention to engage in eLearning. To improve the public opinion regarding the usefulness of eLearning people must be familiarized with eLearning through advertisement and provided opportunities to use eLearning at educational institutions and at work. Providing opportunities for people to use eLearning systems will help improve their computer self-efficacy, which is also an important factor in the use of eLearning.

The perception regarding the ease of use of the system determines people's willingness to use eLearning. Therefore systems that provide good user experiences and those that demand lower learning curves must be employed for eLearning. eLearning systems that are similar in user experience to Web 2.0 technologies such as wikis, blogs, podcasts, social networks, video-sharing, online document editing tools, and virtual worlds have been widely accepted and would be a good choice in this regard.

Introducing eLearning to conscientious individuals would be more effective. They are more likely to consider ways in which the use of eLearning would allow them to be more efficient and perform better. This research has compared, classified and summarized several important models that have been used in technology acceptance and use research into a comprehensive model (Figure 1), so as to help and guide researchers in this field.

\section{References}

Agarwal, R., \& Prasad, J. (1999). Are individual differences germane to the acceptance of new information technology? Decision Science, 30(2), 361-391.

Agarwal, R., Sambamurthy, V., \& Stair, R. M. (2000). The evolving relationship between general and specific computer self-efficacy - An empirical assessment. Information Systems Research, 11(4), 418 430 .

Ajzen, I. (1988). Attitudes, personality, and behavior. Milton-Keynes: Open University Press.

Ajzen, I. (1991). The theory of planned behavior. Organizational Behavior and Human Decision Processes, 50, 179-211.

Ajzen, I., \& Fishbein, M. (1980). Understanding attitudes and predicting social behavior. Englewood Cliffs, NJ: Prentice-Hall.

Amichai-Hamburger, Y., \& Ben-Artzi, E. (2000). The relationship between extraversion and neuroticism and the different uses of the Internet. Computers in Human Behavior, 16, 441-449.

Amichai-Hamburger, Y., \& Ben-Artzi, E. (2003). Loneliness and Internet use. Computers in Human Behavior, 19, 71-80.

Amiel, T., \& Sargent, S. L. (2004). Individual differences in Internet usage motives. Computers in Human Behavior, 20, 711-726.

Barrick, M. R., Mount, M. K., \& Judge, T. A. (2001). Personality and performance at the beginning of the new millennium: What do we know and where do we go next? International Journal of Selection and Assessment, 9(1-2), 9-30.

Brahmasrene, T., \& Lee, J.-W. (2012). Determinants of intent to continue using online learning: A tale of two universities. Interdisciplinary Journal of Information, Knowledge, and Management, 7, 1-20. Retrieved from http://www.ijikm.org/Volume7/IJIKMv7p001-020Brahmasrene540.pdf 
Chau, P. Y. (2001). Influence of computer attitude and self-efficacy on IT usage. Journal of End User Computing, 13(1), 26-33.

Cohen, J. (1988). Statistical power analysis for the behavioral sciences (2nd ed.). New York: Academic Press.

Cohen, J., \& Cohen, P. (1983). Applied multiple regression/correlation analysis for the behavioral sciences. Mahwah, New Jersey: Erlbaum.

Compeau, D. R., \& Higgins, C. A. (1995). Computer self-efficacy - Development of a measure and initial test. MIS Quarterly, 19(2), 189-211.

Conner, M., \& Abraham, C. (2001). Conscientiousness and the theory of planned behavior: Toward a more complete model of the antecedents of intentions and behavior. Personality and Social Psychology Bulletin, 27, 1547-1561.

Costa, P. T., \& McCrae, R. R. (1992). Revised NEO Personality Inventory (NEO PI-R) and NEO FiveFactor Inventory (NEO-FFI) professional manual. Odessa, FL.: Psychological Assessment Resources.

Davis, F. D. (1989). Perceived usefulness, perceived ease of use, and user acceptance of information technology. MIS Quarterly, 13(3), 319-340.

Davis, F. D., Bagozzi, R. P., \& Warshaw, P. R. (1992). Extinsic and intrinsic motivation to use computers in the workplace. Journal of Applied Social Psychology, 22(14), 1111-1132.

Deci, E. L., \& Ryan, R. M. (1985). Intrinsic motivation and self-determinaton in human behaviour. New York: Plenum.

Devaraj, S., Easley, R. F., \& Crant, J. M. (2008). How does personality matter? Relating the five-factor model to technology acceptance and use. Information System Research, 19(1), 93-105.

Doll, J., \& Ajzen, I. (1992). Accessibility and stability of predictors in the theory of planned behavior. Journal of Personality and Social Psychology, 65(5), 754-765.

Driscoll, M. (2002). Web-based training: Designing e-learning experiences. Jossey-Bass.

Duff, A., Boyle, E., Dunleavy, K., \& Ferguson, J. (2004). The relationship between personality, approach to learning and academic performance. Personality and Individual Differences, 36(8), 1907-1920.

Farsides, T., \& Woodfield, R. (2003). Individual differences and undergraduate academic success: The roles of personality, intelligence, and application. Personality and Individual Differences, 34, 12251243.

Fishbein, M., \& Ajzen, I. (1975). Belief, attitude, intention, and behavior: An introduction to theory and research. Reading, MA: Addison-Wesley.

George, D., \& Mallery, P. (2003). SPSS for Windows step by step: A simple guide and reference. 11.0 update. Boston: Allyn and Bacon.

Gong, M., Xu, Y., \& Yu, Y. (2004). An enhanced technology acceptance model for web-based learning. Journal of Information Systems Education, 15(4), 365-373.

Graziano, W. G., \& Eisenberg, N. H. (1997). Agreeableness: A dimension of personality. In R. Hogan, J. Johnston, \& S. Briggs, Handbook of personality psychology (pp. 795-824). San Diego: Academic Press.

Guadagno, R. E., Okdie, B. M., \& Eno, C. A. (2008). Who blogs? Personality predictors of blogging. Computer in Human Behavior, 24(5), 1993-2004.

Horton, W. K. (2000). Designing web-based training: How to teach anyone anything. John Wiley \& Sons.

Huang, Q. V., Davison, R. M., \& Gu, J. B. (2008). Impact of personal and cultural factors on knowledge sharing in China. Asia Pacific Journal of Management, 25(3), 451-471.

Igbaria, M., \& Iivari, J. (1995). Effects of self-efficacy on computer usage. Omega - International Journal of Management Science, 23(6), 587-605. 
Internet Users in Asia. (2011, March). Retrieved December 21, 2011, from Internet Usage Stats: http://www.internetworldstats.com/stats3.htm

Jacques, P. H., Garger, J., Brown, C. A., \& Deale, C. S. (2009). Personality and virtual reality team candidates: The roles of personality traits, technology anxiety and trust as predictors of perceptions of virtual reality teams. Journal of Business and Management, 15(2), 143.

John, O. P., \& Srivastava, S. (1999). Handbook of personality: Theory and research. New York: Guilford Press.

Johnson, R. D., \& Marakas, G. M. (2000). Research report: The role of behavioral modeling in computer skills acquisition - Toward refinement of the model. Information Systems Research, 11(4), 403.

Jose, S. (2010, September 20). Global eLearning market to reach $\$ 107.3$ billion by 2015, according to new report by Global Industry Analysts, Inc. Retrieved December 21, 2011, from PRWeb: http://www.prweb.com/releases/elearning/corporate_elearning/prweb4531974.htm

Kline, R. B. (2005). Principles and practice of structural equation modeling. London: Guilford Press.

Komarraju, M., \& Karau, S. J. (2005). The relationship between the big five personality traits and academic motivation. Personality and Individual Differences, 39, 557-567.

Landers, R. N., \& Lounsbury, J. W. (2004). An investigation of Big Five and narrow personality traits in relation to Internet usage. Computers in Human Behavior, 22(2), 283-293.

Lauriola, M., \& Levin, I. P. (2001, July). Personality traits and risky decision-making in a controlled experimental task: An exploratory study. Personality and Individual Differences, 31(2), 215-226.

Lee, M. K., Cheung, C. M., \& Chen, Z. (2005). Acceptance of Internet-based learning medium: The role of extrinsic and intrinsic motivation. Information and Management, 42(8), 1095-1104.

Maldonado, U. P. T., Khan, G. F., Moon, J., \& Rho, J. J. (2011). E-learning motivation and educational portal acceptance in developing countries. Online Information Review, 35(1), 66-85

Malhotra, Y., \& Galletta, D. F. (2005). A multidimensional commitment model of volitional systems adoption and usage behavior. Journal of MIS, 22(1), 117-151.

Malopinsky, L., Kirkley, J., Stein, R., \& Duffy, T. (2000). An instructional design model for online problem based learning (PBL) environments. The Learning to Teach with Technology Studio. Educational Communications and Technology Conference (AECT). Denver, Colorado.

McCrae, R. R. (1994). A reformulation of Axis II: Personality and personality-related problems. In P. T. Costa, Jr., \& T. A. Widiger, Personality disorders and the five-factor model of personality. Washington, DC: PsycBOOKS.

McCrae, R., \& Costa, P. (1997). Personality trait structures as a human universal. American Psychologist, $52,509-516$.

McElroy, J. C., Hendrickson, A. R., Townsend, A. M., \& DeMarie, S. M. (2007). Dispositional factors in Internet use: Personality versus cognitive style. MIS Quarterely, 31(4), 809 - 820.

Moore, G. C., \& Benbasat, I. (1991). Development of an instrument to measure the perceptions of adopting an information technology innovation. Information Systems Research, 2(3), 173-191.

Neuman, L. W. (2006). Basics of social research : Qualitative and quantitative approaches. Allyn \& Bacon.

Petrides, K. V., Vernon, P. A., Schermer, J. A., Ligthart, L., Boomsma, D. I., \& Veselka, L. (2010). Relationships between trait emotional intelligence and the Big Five in the Netherlands. Personality and Individual Differences, 48, 906-910.

Piedmont, R. L. (1998). The revised NEO Personality Inventory: Clinical and research applications. New York: Plenum Press.

Rosenberg, M. J. (2000). E-Learning: Strategies for delivering knowledge in the digital age. McGraw-Hill. 
Ryan, R. M., \& Deci, E. L. (2000). Self-determination theory and the facilitation of intrinsic motivation, social development, and well-being. American Psychologist, 68-78.

Saadé, R. G., Kira, D., \& Nebebe, F. (2012). Understanding the role of personality traits on beliefs in online learning. Proceedings of Informing Science \& IT Education Conference (InSITE). Montreal, Canada.

Saadé, R. G., Tan, W., \& Nebebe, F. (2008). Impact of motivation on intentions in online learning: Canada vs China. Issues in Informing Science \& Information Technology, 5, 137-147.

Schank, R. C. (2001). Designing world-class e-learning. McGraw-Hill.

Schepers, J., \& Wetzels, M. (2007). A meta-analysis of the technology acceptance model: Investigating subjective norm and moderation effect. Information and Management, 44(1), 90-103.

Schwitzgebel, E. (2011, August). Belief. In E. N. Zalta (Ed.), The Stanford encyclopedia of philosophy (Winter 2011 ed.). Retrieved November 2011 from http://plato.stanford.edu/archives/win2011/entries/belief/

Sobel, M. E. (1986). Some new results on indirect effects and their standard errors in covariance structure models. Sociological Methodology, 16, 159-186.

Straub, D., Boudreau, M.-C., \& Gefen, D. (2004). Validation guidelines for IS positivist research. Communications of the Association for Information Systems, 13(24), 380-427.

Straub, D., Keil, M., \& Brenner, W. (1997). Testing the technology acceptance model across cultures: A three country study. Information and Management, 1(31), 1-11.

Taylor, S., \& Todd, P. A. (1995). Understanding information technology usage: A test of competing models. Information Systems Research, 2(6), 144-178.

Teh, P.-L., Yong, C.-C., Chong, C.-W., \& Yew, S.-Y. (2011). Do the big five personality factors affect knowledge sharing behaviour? A study of Malaysian universities. Malaysian Journal of Library \& Information Science, 16(1), 47-62.

Tryfos, P. (1996). Sampling for applied research: Text and cases. New York: John Wiley \& Sons.

Tsai, S., \& Machado, P. (2002, July). E-Learning basics: Essay. E-learning, online learning, web-based learning, or distance learning: Unveiling the ambiguity in current terminology. eLearn Magazine. Retrieved September 12, 2012, from http://elearnmag.acm.org/featured.cfm?aid=568597

Tuten, T., \& Bosnjak, M. (2001). Understanding differences in web usage: The role of need for cognition and the Five Factor Model of Personality. Social Behavior and Personality, 29(4), 391-398.

Vallerand, R. J. (1997). Toward a hierarchical model of intrinsic and extrinsic motivation. Advances in Experimental Social Psychology, 29, 271-360.

van der Heijden, H. (2004). User acceptance of hedonic information systems. MIS Quarterly, 28(4), 695 704.

Venkatesh, V., \& Davis, F. D. (2000). A model of the antecedents of perceived ease of use: Development and test. Decision Sciences, 27(3), 451-481.

Venkatesh, V., \& Morris, M. G. (2000). Why don't men ever stop to ask for directions? Gender, social influence, and their role in technology acceptance and usage behavior. MIS Quarterly, 24(1), 115-139.

Venkatesh, V., Morris, M. G., Davis, F. D., \& Davis, G. B. (2003). User acceptance of information technology: Toward a unified view. MIS Quarterly, 27, 425-478.

Venkatesh, V., Speier, C., \& Morris, M. G. (2002). User acceptance enablers in individual decision-making about technology: Toward an integrated model. Decision Sciences, 33, 297-316.

Wang, Y. S., Lin, H. H., \& Liao, Y. W. (2010). Investigating the individual difference antecedents of perceived enjoyment in the acceptance of blogging. World Academy of Science, Engineering and Technology, 67. 
Watson, D., \& Clark, L. A. (1997). Extraversion and its positive emotional core. In R. Hogan, J. Johnson, \& S. Briggs (Eds.), Handbook of personality psychology (pp. 767-793). San Diego, CA: Academic Press.

Weinberg, R. S., \& Gould, D. (2010). Foundations of sport and exercise psychology (5th ed.). United States: Human Kinetics.

Wixom, B. H., \& Todd, P. A. (2005). The theoritical integration of user satisfaction and technology acceptance. Information System Research, 6(1), 85.

WordNet Search. (n.d.). Retrieved September 2012, from WordNet Search: http://wordnetweb.princeton.edu/perl/webwn?s=motivation

\section{Appendix}

\section{A1. Notated Questionnaire}

The study questionnaire has been abbreviated and notated to indicate the labels used for variables and indicators and their values.

\section{Section 1}

1. Your gender? (GENDER) $\square$ Male (1) $\square$ Female (2)

2. Have you used eLearning as a mode of learning before undertaking the master degree program at Assumption University? (PREV)
Yes (1)
(2)

3. In which country did (do) you reside mainly while you completed (are completing) the master degree program by eLearning at Assumption

University? (LIVE)

In sections 2, 3, and 4 respondents answered on a measuring scale: Strongly Disagree (1), Disagree (2), Neutral (3), Agree (4), and Strongly Agree (5).

\section{Section 2}

\begin{tabular}{|c|l|c|l|}
\hline Indicator & I see myself as someone who ...... & Indicator I see myself as someone who ....... \\
\hline PE1 & $\begin{array}{l}\text { finds using a computer to be en- } \\
\text { joyable }\end{array}$ & CS9 & is not easily distracted \\
\hline PE2 & $\begin{array}{l}\text { finds using a computer is a pleas- } \\
\text { ant way to pass time }\end{array}$ & NE1 & is not depressed \\
\hline PE3 & has fun using a computer & NE2 & is relaxed and handles stress well \\
\hline EX1 & is talkative & NE3 & does not worry a lot \\
\hline EX2 & is full of energy & NE4 & is emotionally stable and not easily upset \\
\hline EX3 & is enthusiastic & NE5 & is not moody \\
\hline EX4 & is not quiet & NE6 & remains calm in tense situations \\
\hline EX5 & has an assertive personality & NE7 & hardly ever gets nervous \\
\hline EX6 & is not shy and inhibited & OP1 & is original and comes up with new ideas \\
\hline EX7 & is outgoing and sociable & OP2 & is curious about many different things \\
\hline
\end{tabular}




\begin{tabular}{|c|c|c|c|}
\hline AG1 & rarely finds fault with others & OP3 & is ingenious and a deep thinker \\
\hline AG2 & is helpful and unselfish with others & OP4 & has an active imagination \\
\hline AG3 & rarely starts quarrels with others & OP5 & is inventive \\
\hline AG4 & has a forgiving nature & OP6 & values artistic and aesthetic experiences \\
\hline AG5 & is trusting & OP7 & is sophisticated in art, music, or literature \\
\hline AG6 & is considerate and kind & CSE1 & $\begin{array}{l}\text { can work out how to use a computer sys- } \\
\text { tem without a lot of help from others }\end{array}$ \\
\hline AG7 & is not rude to others & CSE2 & $\begin{array}{l}\text { can learn quickly to use a new computer } \\
\text { system }\end{array}$ \\
\hline AG8 & likes to cooperate with others & CSE3 & $\begin{array}{l}\text { feels confident in being able to download } \\
\text { information from the Internet }\end{array}$ \\
\hline CS1 & does a thorough job & CSE4 & $\begin{array}{l}\text { does not need to consult manuals to be } \\
\text { able to use a computer system }\end{array}$ \\
\hline CS2 & is not careless & CSE5 & $\begin{array}{l}\text { feels confident in using Internet search } \\
\text { engines (e.g. Google and Yahoo) }\end{array}$ \\
\hline CS3 & is a reliable worker & CSE6 & $\begin{array}{l}\text { rarely needs to ask others for help when } \\
\text { using computers }\end{array}$ \\
\hline CS4 & is organized & CSE7 & $\begin{array}{l}\text { feels comfortable when I am using the } \\
\text { Internet }\end{array}$ \\
\hline CS5 & is not lazy & CSE8 & $\begin{array}{l}\text { feels confident about their ability to use } \\
\text { computers }\end{array}$ \\
\hline CS6 & perseveres until a task is finished & CSE9 & $\begin{array}{l}\text { can teach myself how to use a computer } \\
\text { system }\end{array}$ \\
\hline CS7 & does things efficiently & CSE10 & can help others to use a computer \\
\hline CS8 & $\begin{array}{l}\text { makes plans and follows them } \\
\text { through }\end{array}$ & & \\
\hline
\end{tabular}

\section{Section 3}

\begin{tabular}{|c|l|c|l|}
\hline Indicator & The technology system: & Indicator & The technology system: \\
\hline PU1 & improved my learning performance & PEU1 & was easy for me to learn to use \\
\hline PU2 & $\begin{array}{l}\text { enables me to do my study more effi- } \\
\text { ciently }\end{array}$ & PEU2 & $\begin{array}{l}\text { made it easy to do what I wanted } \\
\text { to do }\end{array}$ \\
\hline PU3 & $\begin{array}{l}\text { enables me to do my study more effec- } \\
\text { tively }\end{array}$ & PEU3 & was easy for me to interact with \\
\hline PU4 & increases my productivity in studying & PEU4 & was flexible \\
\hline PU5 & makes it easier for me to learn & PEU5 & was easy to use \\
\hline PU6 & was useful for my study & PEU6 & was "user friendly" \\
\hline
\end{tabular}




\begin{tabular}{|c|c|}
\hline \multicolumn{2}{|r|}{$\begin{array}{l}\text { Indicator Statements about eLearning as a mode of learning and study: } \\
\text { S }\end{array}$} \\
\hline SN1 & Most people who are important to me think that I should study in eLearning mode \\
\hline SN2 & People whose opinions I value approve of me learning in eLearning mode \\
\hline SN3 & $\begin{array}{l}\text { My colleagues and friends think that eLearning is an appropriate mode of learning and } \\
\text { study for me }\end{array}$ \\
\hline SN4 & My family considers eLearning to be an appropriate mode of learning and study for me \\
\hline
\end{tabular}

\section{Section 4}

\begin{tabular}{|c|l|}
\hline Indicator & $\begin{array}{l}\text { Statements about your intentions toward eLearning as a mode of study and } \\
\text { learning in the future: }\end{array}$ \\
\hline BI1 & I would be pleased to study in eLearning mode in the future \\
\hline BI2 & I intend to engage in eLearning to improve my study performance as often as needed \\
\hline BI3 & I intend to engage in eLearning routinely \\
\hline BI4 & I intend to use the eLearning mode of study again \\
\hline BI5 & I intend to use eLearning for future study or training \\
\hline BI6 & I would seriously consider studying in eLearning mode again \\
\hline
\end{tabular}


Table A1: Factor Analysis (Rotated component matrix)

\begin{tabular}{|c|c|c|c|c|c|c|c|c|c|c|c|}
\hline \multirow{2}{*}{ Indicator } & \multicolumn{11}{|c|}{ Component (Latent Variable) } \\
\hline & CSE & CS & NE & AG & BI & OP & PEU & $\mathbf{E X}$ & SN & PU & PE \\
\hline \multirow{10}{*}{$\begin{array}{ll}\text { CSE2 } \\
\text { CSE1 } \\
\text { CSE4 } \\
\text { CSE7 } \\
\text { CSE6 } \\
\text { CSE9 } \\
\text { CSE5 } \\
\text { CSE10 } \\
\text { CSE8 } \\
\text { CSE3 }\end{array}$} & .796 & .064 & .111 & .018 & .134 & .223 & .065 & .105 & .033 & .145 & .149 \\
\hline & .795 & .025 & .122 & -.004 & .115 & .195 & .067 & .123 & .050 & .156 & .163 \\
\hline & .791 & .070 & .162 & .143 & .058 & .200 & .087 & .057 & .080 & .124 & .153 \\
\hline & .779 & .166 & .108 & .213 & .055 & .080 & .127 & .042 & .037 & .050 & .227 \\
\hline & .777 & .116 & .067 & .129 & .069 & .102 & .108 & .046 & .085 & .045 & .190 \\
\hline & .777 & .104 & .105 & .095 & .148 & .137 & .111 & .069 & .024 & .181 & .241 \\
\hline & .775 & .174 & .060 & .173 & .106 & .108 & .189 & .094 & .105 & .014 & .155 \\
\hline & .770 & .020 & .144 & .001 & .142 & .086 & .124 & .081 & .075 & .233 & .279 \\
\hline & .763 & .126 & .081 & .145 & .076 & .117 & .141 & .021 & .046 & .130 & .261 \\
\hline & .743 & .075 & .095 & .085 & .137 & .138 & .168 & .069 & .028 & .097 & .198 \\
\hline \multirow{9}{*}{$\begin{array}{l}\text { CS5 } \\
\text { CS3 } \\
\text { CS4 } \\
\text { CS6 } \\
\text { CS8 } \\
\text { CS7 } \\
\text { CS2 } \\
\text { CS1 } \\
\text { CS9 }\end{array}$} & .019 & .760 & .204 & .118 & .058 & .029 & .071 & .119 & .132 & .019 & .035 \\
\hline & .099 & .759 & .023 & .248 & .039 & .181 & .155 & .124 & .062 & .052 & .016 \\
\hline & .128 & .756 & .102 & .180 & -.044 & .097 & .002 & .122 & .093 & .068 & -.054 \\
\hline & .066 & .736 & .062 & .236 & .166 & .090 & .059 & .164 & .113 & .160 & .044 \\
\hline & .088 & .722 & .091 & .100 & .049 & .089 & -.050 & .158 & .014 & .268 & -.001 \\
\hline & .122 & .720 & .106 & .173 & .097 & .076 & .065 & .272 & .067 & .174 & -.003 \\
\hline & .098 & .718 & .184 & .214 & .112 & .063 & .145 & .123 & .090 & -.066 & .078 \\
\hline & .048 & .706 & .092 & .227 & .064 & .189 & .118 & .195 & .103 & .119 & -.028 \\
\hline & .139 & .625 & .356 & .118 & -.002 & .189 & .016 & .094 & .011 & .075 & -.009 \\
\hline \multirow{7}{*}{$\begin{array}{l}\text { NE4 } \\
\text { NE3 } \\
\text { NE5 } \\
\text { NE2 } \\
\text { NE7 } \\
\text { NE6 } \\
\text { NE1 }\end{array}$} & .103 & .089 & .845 & .202 & .100 & .098 & .038 & .065 & .121 & .044 & .019 \\
\hline & .110 & .038 & .828 & .125 & .022 & .080 & .050 & .125 & .098 & .023 & -.083 \\
\hline & .045 & .095 & .822 & .177 & .142 & .089 & -.009 & .139 & .136 & .075 & .044 \\
\hline & .078 & .071 & .814 & .080 & -.002 & .101 & .010 & .173 & .081 & -.018 & .026 \\
\hline & .094 & .139 & .773 & .084 & .152 & .177 & -.017 & .158 & -.035 & .061 & .037 \\
\hline & .080 & .119 & .759 & .157 & .061 & .166 & -.006 & .108 & $\begin{array}{l}.119 \\
\end{array}$ & .120 & .052 \\
\hline & .112 & .288 & .709 & .165 & .015 & .152 & .130 & .143 & .098 & -.079 & .048 \\
\hline \multirow{8}{*}{\begin{tabular}{|l} 
AG5 \\
AG3 \\
AG7 \\
AG6 \\
AG4 \\
AG1 \\
AG2 \\
AG8
\end{tabular}} & .060 & .149 & .066 & .830 & .049 & -.007 & .013 & .051 & .044 & .096 & .069 \\
\hline & .106 & .102 & .203 & .784 & .009 & .019 & .080 & .004 & .151 & .006 & .061 \\
\hline & .077 & .131 & .139 & .782 & .064 & .030 & .108 & .080 & .052 & .087 & .045 \\
\hline & .114 & .197 & .029 & .779 & .103 & .049 & .090 & .141 & -.020 & .102 & .100 \\
\hline & .088 & .110 & .241 & .744 & .067 & .092 & .032 & .114 & .114 & .018 & .088 \\
\hline & .090 & .104 & .212 & .707 & .028 & .106 & -.014 & .057 & .130 & .102 & .036 \\
\hline & .099 & .374 & .066 & .645 & .110 & .046 & .131 & .186 & .006 & .019 & -.027 \\
\hline & .022 & .261 & .154 & .624 & .109 & .132 & .075 & .231 & .094 & .116 & -.038 \\
\hline \multirow{6}{*}{$\begin{array}{l}\text { BI4 } \\
\text { BI5 } \\
\text { BI1 } \\
\text { BI6 } \\
\text { BI3 } \\
\text { BI2 }\end{array}$} & .078 & .003 & .042 & .037 & .878 & .038 & .168 & .019 & .222 & .191 & .046 \\
\hline & .112 & .027 & .022 & .041 & .857 & .073 & .136 & .078 & .211 & .197 & .095 \\
\hline & .046 & .055 & .047 & .068 & .848 & .040 & .144 & .042 & .228 & .215 & .071 \\
\hline & .086 & .072 & .050 & .081 & .839 & .036 & .145 & .055 & .267 & .179 & .094 \\
\hline & .107 & .028 & .120 & .042 & .792 & -.004 & .202 & .014 & .300 & .193 & .054 \\
\hline & .080 & .067 & .117 & .072 & .782 & -.012 & .187 & .010 & .308 & .252 & .039 \\
\hline \multirow{7}{*}{$\begin{array}{l}\text { OP5 } \\
\text { OP4 } \\
\text { OP7 } \\
\text { OP3 } \\
\text { OP1 } \\
\text { OP6 } \\
\text { OP2 }\end{array}$} & .066 & .074 & .165 & .005 & .044 & .825 & .104 & .165 & .088 & .074 & .068 \\
\hline & .163 & .095 & .043 & .000 & .091 & .817 & .072 & .121 & .038 & .182 & .022 \\
\hline & .041 & .048 & .013 & -.025 & -.046 & .768 & .095 & .070 & .010 & .113 & .175 \\
\hline & .157 & .065 & .087 & .091 & .069 & .765 & .062 & .232 & -.012 & .045 & .081 \\
\hline & .133 & .096 & .186 & .055 & .027 & .763 & .037 & .185 & -.028 & .068 & -.070 \\
\hline & .103 & .080 & .212 & .088 & -.006 & .751 & .103 & .063 & .064 & .060 & .071 \\
\hline & .142 & .159 & .103 & .143 & .083 & .717 & .134 & .152 & -.066 & -.003 & .033 \\
\hline \multirow{3}{*}{$\begin{array}{l}\text { PEU4 } \\
\text { PEU5 } \\
\text { PEU6 }\end{array}$} & .064 & .070 & -.070 & .071 & .114 & .092 & .821 & .023 & .135 & .248 & .056 \\
\hline & .140 & .042 & .077 & .038 & .187 & .116 & .818 & .065 & .098 & .287 & .077 \\
\hline & .119 & .069 & .096 & .003 & .186 & .044 & .800 & .084 & .113 & .241 & .075 \\
\hline
\end{tabular}




\begin{tabular}{|c|c|c|c|c|c|c|c|c|c|c|c|}
\hline \multirow{3}{*}{$\begin{array}{l}\text { PEU2 } \\
\text { PEU3 } \\
\text { PEU1 }\end{array}$} & .074 & .012 & -.019 & .055 & .175 & .061 & .776 & .078 & .125 & .349 & .099 \\
\hline & .090 & .079 & .019 & .073 & .116 & .128 & .744 & .072 & .174 & .331 & .173 \\
\hline & .100 & -.008 & -.001 & .078 & .196 & .114 & .742 & .065 & .136 & .282 & .160 \\
\hline \multirow{7}{*}{$\begin{array}{l}\text { EX1 } \\
\text { EX4 } \\
\text { EX2 } \\
\text { EX3 } \\
\text { EX7 } \\
\text { EX6 } \\
\text { EX5 }\end{array}$} & .014 & .072 & .019 & .007 & .026 & .082 & .042 & .838 & .028 & .079 & .211 \\
\hline & .073 & .058 & .067 & .063 & -.067 & .147 & .121 & .820 & .046 & .047 & .002 \\
\hline & .006 & .247 & .088 & .199 & .057 & .086 & -.004 & .733 & .054 & .166 & .093 \\
\hline & .059 & .263 & .105 & .151 & .055 & .107 & .106 & .727 & .078 & .145 & .092 \\
\hline & .010 & .032 & .161 & .089 & .024 & .174 & .046 & .723 & .060 & .087 & .079 \\
\hline & .068 & .107 & .273 & .081 & .114 & .171 & -.050 & .698 & .153 & -.020 & .023 \\
\hline & .126 & .176 & .178 & .047 & .119 & .205 & .181 & .695 & .067 & -.003 & .016 \\
\hline \multirow{4}{*}{$\begin{array}{l}\text { SN3 } \\
\text { SN4 } \\
\text { SN2 } \\
\text { SN1 }\end{array}$} & .016 & .067 & .048 & .025 & .187 & -.016 & .114 & .047 & .857 & .087 & .004 \\
\hline & .018 & .037 & .070 & .058 & .219 & -.073 & .142 & .036 & .854 & .082 & -.039 \\
\hline & .031 & .045 & .074 & .052 & .241 & .062 & .106 & .096 & .848 & .122 & .040 \\
\hline & .005 & .033 & .070 & .056 & .247 & -.007 & .047 & .035 & .843 & .185 & .064 \\
\hline \multirow{4}{*}{$\begin{array}{l}\text { PU2 } \\
\text { PU3 } \\
\text { PU1 } \\
\text { PU4 } \\
\end{array}$} & .092 & .071 & .034 & .016 & .195 & .025 & .297 & .072 & .178 & .830 & .090 \\
\hline & .108 & .067 & .014 & .021 & .213 & .038 & .333 & .067 & .180 & .805 & .065 \\
\hline & .056 & .033 & -.026 & .056 & .262 & .100 & .352 & .061 & .098 & .754 & .075 \\
\hline & .051 & .081 & -.008 & .122 & .253 & .127 & .398 & .035 & .167 & .715 & .056 \\
\hline \multirow{3}{*}{$\begin{array}{l}\text { PE2 } \\
\text { PE1 } \\
\text { PE3 }\end{array}$} & .108 & -.051 & -.081 & .018 & -.011 & .073 & .133 & .021 & .030 & .040 & .906 \\
\hline & .172 & -.061 & .014 & .053 & .086 & -.001 & .085 & .093 & -.016 & -.006 & .894 \\
\hline & .179 & -.009 & .012 & -.014 & .043 & .005 & -.009 & .068 & .005 & .093 & .892 \\
\hline
\end{tabular}

Table A2: Total variance explained

\begin{tabular}{|c|c|c|c|c|c|c|}
\hline \multirow{2}{*}{$\begin{array}{c}\text { Component } \\
\text { (Latent Varia- } \\
\text { ble) }\end{array}$} & \multicolumn{3}{|c|}{ Initial Eigenvalues } & \multicolumn{3}{|c|}{ Rotation Sums of Squared Loadings } \\
\hline & Total & $\begin{array}{c}\text { Percentage of } \\
\text { Variance }\end{array}$ & $\begin{array}{c}\text { Cumulative } \\
\text { Percent }\end{array}$ & Total & $\begin{array}{l}\text { Percentage } \\
\text { of Variance }\end{array}$ & $\begin{array}{l}\text { Cumulative } \\
\text { Percent }\end{array}$ \\
\hline CSE & 19.216 & 27.064 & 27.064 & 6.578 & 9.265 & 9.265 \\
\hline $\mathrm{CS}$ & 7.374 & 10.386 & 37.450 & 5.593 & 7.878 & 17.143 \\
\hline $\mathrm{NE}$ & 5.595 & 7.880 & 45.330 & 5.341 & 7.523 & 24.666 \\
\hline $\mathrm{AG}$ & 4.130 & 5.818 & 51.148 & 5.198 & 7.321 & 31.986 \\
\hline BI & 3.845 & 5.415 & 56.563 & 5.112 & 7.200 & 39.187 \\
\hline OP & 2.884 & 4.061 & 60.624 & 4.957 & 6.981 & 46.168 \\
\hline PEU & 2.776 & 3.910 & 64.535 & 4.831 & 6.804 & 52.972 \\
\hline EX & 2.408 & 3.392 & 67.926 & 4.724 & 6.654 & 59.626 \\
\hline SN & 1.832 & 2.580 & 70.506 & 3.811 & 5.367 & 64.993 \\
\hline PU & 1.799 & 2.533 & 73.039 & 3.808 & 5.363 & 70.356 \\
\hline $\mathrm{PE}$ & 1.258 & 1.771 & 74.811 & 3.163 & 4.455 & 74.811 \\
\hline \multicolumn{7}{|c|}{$\begin{array}{l}\text { Notes: (a)Extraction Method: Principal Component Analysis, Rotation Method:Equamax with Kaiser } \\
\text { Normalization, Rotation converged in } 9 \text { iterations (b)Kaiser-Meyer-Olkin Measure of Sampling Adequacy } \\
0.903 \text {, (c)Bartlett's Test of Sphericity (Approx. Chi-Square16456.592, Degrees of Freedom 2485, Sig. } \\
0.000 \text { ), (e) Components with eigenvalues less than } 1 \text { are not shown. }\end{array}$} \\
\hline
\end{tabular}

Table A3: Cronbach alpha coefficients

\begin{tabular}{|l|c|l|c|}
\hline \multicolumn{1}{|c|}{ Latent Variable (Indicators) } & Alpha & \multicolumn{1}{|c|}{ Latent Variable (Indicators) } & Alpha \\
\hline CSE (CSE1 -10) & 0.961 & PEU (PEU1 - 6) & 0.956 \\
\hline CS (CS1 - 9) & 0.930 & EX (EX1 - 7) & 0.910 \\
\hline NE (NE1 - 7) & 0.936 & SN (SN1 - 4) & 0.924 \\
\hline AG (AG1 - 8) & 0.919 & PU (PU1 - 4) & 0.939 \\
\hline BI (BI1 -6) & 0.966 & PE (PE1 - 3) & 0.913 \\
\hline OP (OP1 - 7) & 0.919 & \multicolumn{2}{|l}{}
\end{tabular}


Table A4: Descriptive statistics for model variables

\begin{tabular}{|c|c|c|c|c|}
\hline Variable (Indicators) & Mean & Standard Deviation & Skewness & Kurtosis \\
\hline Perceived Enjoyment (PE) & 4.0696 & .71690 & -.572 & .288 \\
\hline PE1 & 4.17 & .715 & -.526 & -.006 \\
\hline PE2 & 3.99 & .821 & -.640 & .305 \\
\hline PE3 & 4.05 & .794 & -.483 & -.054 \\
\hline Extraversion (EX) & 3.65 & .572 & .071 & -.049 \\
\hline EX1 & 3.51 & .763 & .337 & -.354 \\
\hline EX2 & 3.76 & .693 & -.087 & -.213 \\
\hline EX3 & 3.84 & .659 & -.158 & -.006 \\
\hline EX4 & 3.63 & .751 & -.079 & -.308 \\
\hline EX5 & 3.60 & .678 & .383 & -.441 \\
\hline EX6 & 3.63 & .702 & -.036 & -.227 \\
\hline EX7 & 3.61 & .727 & -.073 & -.248 \\
\hline Agreeableness (AG) & 3.98 & .536 & -.434 & .209 \\
\hline AG1 & 3.71 & .614 & -.042 & -.192 \\
\hline AG2 & 4.03 & .612 & -.228 & .445 \\
\hline AG3 & 3.86 & .698 & -.154 & -.193 \\
\hline AG4 & 3.91 & .678 & -.203 & -.046 \\
\hline AG5 & 4.07 & .724 & -.554 & .362 \\
\hline AG6 & 4.13 & .684 & -.397 & .000 \\
\hline AG7 & 4.10 & .714 & -.350 & -.338 \\
\hline AG8 & 4.03 & .628 & -.319 & .577 \\
\hline Conscientiousness (CS) & 3.92 & .532 & -.093 & .055 \\
\hline CS1 & 4.01 & .632 & -.106 & -.151 \\
\hline $\mathrm{CS} 2$ & 3.77 & .718 & -.221 & .279 \\
\hline$\overline{\mathrm{CS} 3}$ & 4.12 & .623 & -.390 & .759 \\
\hline CS4 & 4.02 & .660 & -.102 & -.413 \\
\hline CS5 & 3.85 & .713 & -.239 & .301 \\
\hline CS6 & 4.05 & .679 & -.142 & -.560 \\
\hline CS7 & 4.00 & .599 & -.226 & .582 \\
\hline CS8 & 3.90 & .652 & -.158 & .003 \\
\hline CS9 & 3.58 & .714 & -.259 & .248 \\
\hline Neuroticism (NE) & 3.52 & .624 & -.421 & .798 \\
\hline NE1 & 3.59 & .736 & -.285 & .519 \\
\hline NE2 & 3.55 & .689 & -.331 & .326 \\
\hline NE3 & 3.39 & .776 & -.227 & .000 \\
\hline NE4 & 3.52 & .794 & -.231 & -.158 \\
\hline NE5 & 3.58 & .753 & -.269 & .084 \\
\hline NE6 & 3.63 & .673 & -.430 & .593 \\
\hline NE7 & 3.40 & .712 & -.141 & .046 \\
\hline Openness (OP) & 3.77 & .573 & .032 & -.103 \\
\hline OP1 & 3.83 & .683 & -.151 & -.109 \\
\hline OP2 & 3.88 & .710 & -.224 & -.125 \\
\hline OP3 & 3.78 & .702 & .119 & -.595 \\
\hline OP4 & 3.83 & .681 & -.240 & .072 \\
\hline OP5 & 3.64 & .711 & .111 & -.364 \\
\hline OP6 & 3.74 & .684 & -.072 & -.197 \\
\hline OP7 & 3.69 & .722 & .089 & -.437 \\
\hline Computer Self-Efficacy (CSE) & 4.03 & .624 & -.245 & -.353 \\
\hline CSE1 & 3.89 & .746 & -.291 & -.180 \\
\hline CSE2 & 3.91 & .759 & -.290 & -.272 \\
\hline CSE3 & 4.02 & .710 & -.165 & -.596 \\
\hline
\end{tabular}




\begin{tabular}{|l|c|c|c|c|}
\hline CSE4 & 3.86 & .764 & -.077 & -.627 \\
\hline CSE5 & 4.25 & .662 & -.490 & .013 \\
\hline CSE6 & 3.93 & .759 & -.214 & -.480 \\
\hline CSE7 & 4.26 & .635 & -.377 & -.199 \\
\hline CSE8 & 4.08 & .679 & -.256 & -.282 \\
\hline CSE9 & 4.07 & .748 & -.352 & -.473 \\
\hline CSE10 & 4.00 & .791 & -.338 & -.516 \\
\hline Perceived Usefulness (PU) & 4.15 & .638 & -.626 & .920 \\
\hline PU1 & 4.16 & .679 & -.449 & .097 \\
\hline PU2 & 4.17 & .700 & -.820 & 1.688 \\
\hline PU3 & 4.19 & .666 & -.646 & .957 \\
\hline PU4 & 4.08 & .727 & -.384 & -.268 \\
\hline Perceived Ease of Use (PEU) & 4.16 & .608 & -.510 & .653 \\
\hline PEU1 & 4.19 & .672 & -.564 & .531 \\
\hline PEU2 & 4.17 & .692 & -.751 & 1.543 \\
\hline PEU3 & 4.07 & .701 & -.378 & -.019 \\
\hline PEU4 & 4.18 & .698 & -.478 & -.081 \\
\hline PEU5 & 4.19 & .654 & -.476 & .409 \\
\hline PEU6 & 4.15 & .694 & -.426 & -.085 \\
\hline Subjective Norms (SN) & 3.66 & .708 & -.287 & .799 \\
\hline SN1 & 3.56 & .831 & -.051 & -.124 \\
\hline SN2 & 3.73 & .766 & -.360 & .496 \\
\hline SN3 & 3.63 & .767 & -.284 & .361 \\
\hline SN4 & 3.72 & .772 & -.325 & .410 \\
\hline Behavioral Intention (BI) & 3.84 & .782 & -.197 & -.453 \\
\hline BI1 & 3.96 & .851 & -.517 & .064 \\
\hline BI2 & 3.90 & .801 & -.188 & -.657 \\
\hline BI3 & 3.76 & .821 & -.066 & -.674 \\
\hline BI4 & 3.80 & .857 & -.183 & -.514 \\
\hline BI5 & 3.85 & .836 & -.339 & -.244 \\
\hline BI6 & 3.74 & .910 & -.147 & -.707 \\
\hline
\end{tabular}

Table A5: Correlations among model variables

\begin{tabular}{|c|c|c|c|c|c|c|c|c|c|c|}
\hline Model Variables & $\mathrm{PE}$ & EX & AG & CS & NE & $\mathrm{OP}$ & CSE & PU & PEU & $\mathrm{SN}$ \\
\hline Perceived Enjoyment (PE) & 1 & & & & & & & & & \\
\hline Extraversion $(\mathrm{EX})$ & .167 & 1 & & & & & & & & \\
\hline Agreeableness (AG) & .100 & .336 & 1 & & & & & & & \\
\hline Conscientiousness (CS) & .022 & .437 & .512 & 1 & & & & & & \\
\hline Neuroticism (NE) & .039 & .379 & .409 & .407 & 1 & & & & & \\
\hline Openness (OP) & .135 & .403 & .233 & .337 & .346 & 1 & & & & \\
\hline Computer Self-Efficacy (CSE) & .402 & .268 & .314 & .326 & .312 & .378 & 1 & & & \\
\hline Perceived Usefulness (PU) & .177 & .238 & .232 & .272 & .136 & .249 & .335 & 1 & & \\
\hline Perceived Ease of Use (PEU) & .231 & .241 & .233 & .242 & .146 & .279 & .363 & .704 & 1 & \\
\hline Subjective Norms (SN) & .057 & .193 & .208 & .213 & .224 & .076 & .171 & .386 & .343 & 1 \\
\hline Behavioral Intention (BI) & 148 & .188 & .232 & .225 & .222 & 157 & .312 & .550 & .466 & .547 \\
\hline
\end{tabular}


Table A6: Analysis of the final model

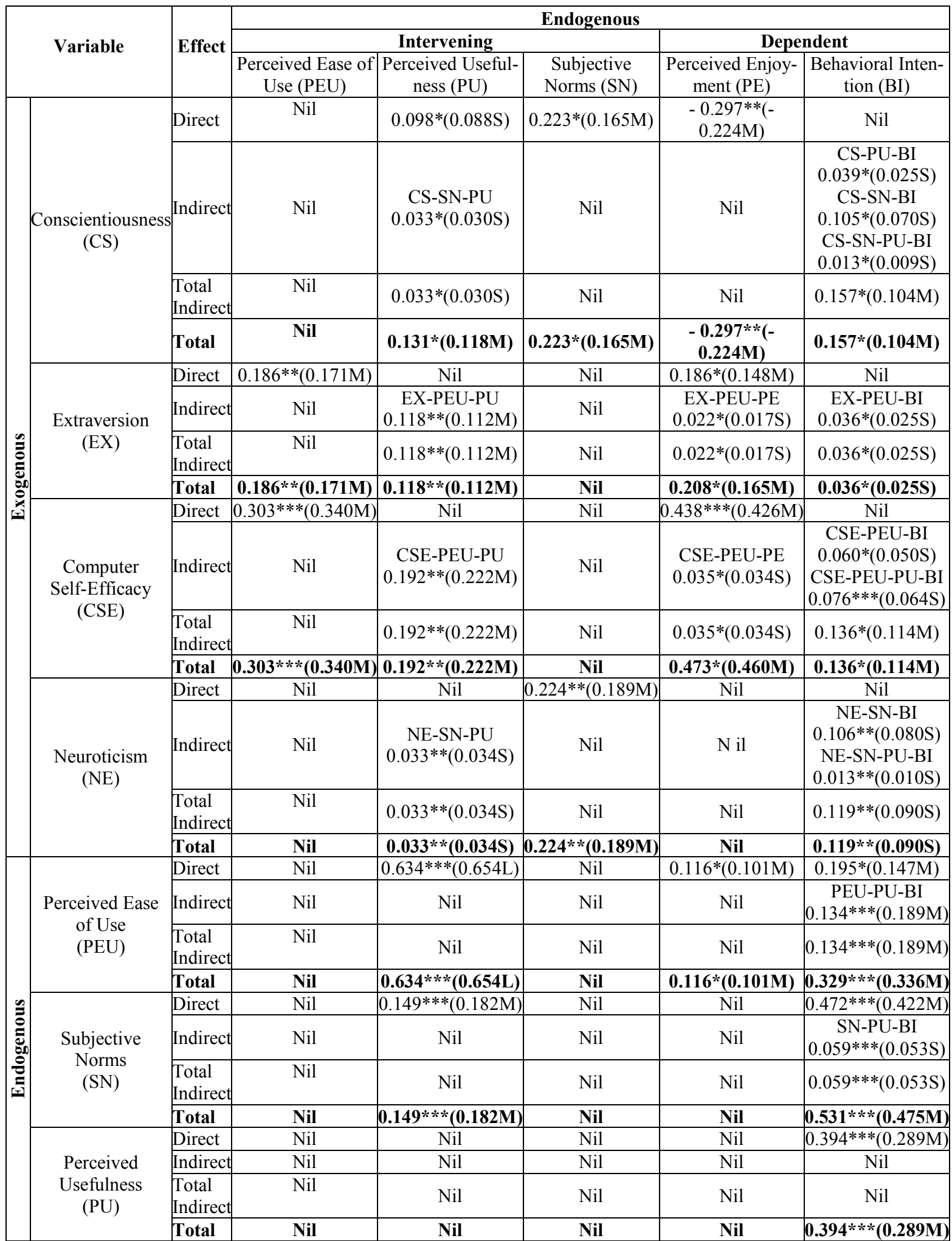




\section{Biography}

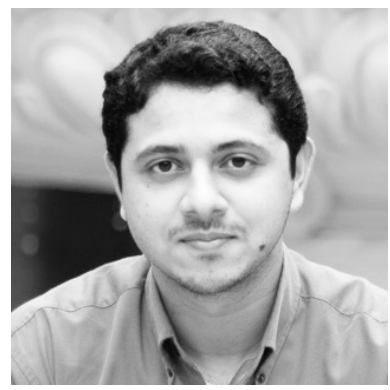

Alfie Chacko Punnoose is a System Analyst at Assumption University of Thailand. He holds a B.Eng in Computer Engineering, M.S. in Computer and Engineering Management and a Ph.D. in IT from Assumption University. With this diverse background in computer technology, his field of interest range from the micro-level of technology development to the macro-level of usage and acceptance of technology. The research topics of his interested are Acceptance and Effectiveness of Information Systems, Human Behavior and Information Technology, Software Engineering and Programming, Object-Oriented Analysis and Design, Web 2.0 and Semantic Web, eLearning and eCommerce. His research interests are driven by the curiosity to know and the urge to learn. Thus he asks, "Why do I exist if it's not to find the cause of my own existence?" 